\title{
BAMBUSOIDEAE (POACEAE) NO PARQUE ESTADUAL DE IBITIPOCA, MINAS GERAIS, BRASIL ${ }^{1}$
}

\author{
FABRÍCIO MOREIRA FERREIRA*, ANDREA FERREIRA DA COSTA** \& \\ RAFAELA CAM POSTRINI FORZZA*** \\ * Departamento de Ciências Biológicas, Universidade Estadual de Feira de Santana, km 03, BR 116, 44031-460 \\ Feira de Santana, BA, B rasil. A utor para correspondência: fmoreiraf@ yahoo.com.br. \\ ** Departamento de B otânica, M useu Nacional, Quinta da B oa Vista, s.n., \\ São Cristóvão, 20940-040 - Rio de Janeiro, RJ, B rasil. \\ *** J ardim B otânico do Rio de J aneiro, Rua Pacheco L eão 915, 22460-030 - Rio de J aneiro, RJ, B rasil.
}

\begin{abstract}
The Bambusoideae (Poaceae) in the Parque Estadual de Ibitipoca, M inas Gerais, B razil]. The Parque Estadual de Ibitipoca (PEIB) is situated in the southeastern state of M inas Gerais, in the municipalities of Lima Duarte and Santa Rita do Ibitipoca. Rough topography and different types of soils al low a heterogeneous plant cover mostly made up of a mosaic of communities in the PEIB. The campos rupestres are the predominant vegetation. The present study is a floristic survey of the subfamily Bambusoideae in the PEIB. A total of 11 species belonging to four genera (Aulonemia, Chusquea, M erostachys and Parodiolyra) was found. A dditionally, the occurrence of Aulonemia fimbriatifolia in the PEIB is also reported for the first time in M inas Gerais.
\end{abstract}

\begin{abstract}
Resumo - [B ambusoideae (Poaceae) no Parque Estadual de Ibitipoca, M inas Gerais, B rasil]. 0 Parque Estadual de Ibitipoca (PEIB ) situa-se no sudeste de M inas Gerais, nos municípios de Lima Duarte e Santa Rita do I bitipoca. A topografia acidentada e variados tipos de solos permitem que a cobertura vegetal do Parque apresente-se de forma heterogênea, sendo os campos rupestres a cobertura predominante. 0 presente estudo teve por finalidade inventariar a subfamília Bambusoideae no PEIB. Foram registradas 11 espécies distribuídas em quatro gêneros (Aulonemia, C husquea, M erostachys e Parodiolyra). R egistra-se, pela primeira vez, a ocorrência de Aulonemia fimbriatifolia em M inas Gerais.
\end{abstract}

Key words: Gramineae, bamboos, montane forests, Serra da M antiqueira, floristic survey

\section{Introdução}

Poaceae (Gramineae) é uma das maiores famílias de fanerógamas e está intimamente relacionada com o processo evolutivo de grandes mamíferos e da própria espécie humana (deWet 1981, Stebbins 1981). A família ocupa um papel fundamental na atividade econômica do homem e na composição de comunidades vegetais (Tzvelev 1989), compreendendo cerca de um terço da cobertura vegetal do planeta (Shantz 1954, J acobs et al. 1999).

A lém das formações campestres, as gramíneas são importantes na composição florística das florestas tropicais e subtropicais, representadas, principalmente, por Bambusoideae (Calderón \& Soderstrom 1980). Os bambus estão tipicamente associados a formações florestais, porém, existem espécies adaptadas a outros tipos de ambientes como o cerrado, campo rupestre e campo de altitude (Soderstrom 1981).

A subfamília B ambusoideae é constituída por aproximadamente 60 a 70 gêneros e 1.200 espécies com ampla distribuição latitudinal, $46^{\circ} \mathrm{N}$ e $47^{\circ} \mathrm{S}$, e altitudinal, desde o nível do mar até cerca de $4.000 \mathrm{~m}$ de altitude (Soderstrom \& Calderón 1974, Soderstrom et al. 1988, GPW G 2001). A maior diversidade do grupo na região neotropical concentra-se no B rasil, em especial, nas florestas costeiras da B ahia, área de grande riqueza e endemismo de espécies (Clark 1990, Judziewicz et al. 1999).

Os bambus constituem um grupo monofilético dentro de Poaceae suportado tanto por dados morfológicos quanto moleculares (Clark et al. 1995, Zhang \& Clark 2000). A atual circunscrição da subfamília Bambusoideae engloba apenas duas tribos, $B$ ambuseae, formada pelos bambus lenhosos e

\footnotetext{
${ }^{1}$ Parte da dissertação de mestrado do primeiro autor, desenvolvida no Programa de Pós-Graduação em Ciências Biológicas (Botânica) do M useu N acional, UFRJ, Rio de Janeiro.
} 
Olyreae, representada pelos bambus herbáceos (Zhang \& Clark 2000).

N o B rasil os bambus estão representados por 34 gêneros (16 herbáceos e 18 lenhosos) e 230 espécies (75 herbáceos e 155 lenhosos), sendo que 45 espécies de Olyreae e 129 de $B$ ambuseae são endêmicas, o que corresponde a, respectivamente, a $60 \%$ e $83 \%$ da flora nativa de bambus (Filgueiras \& Santos-G onçal ves 2004).

A Serra de I bitipoca faz parte do complexo da M antiqueira, e localiza-se no sul do estado de M inas Gerais, em uma das áreas de transição entre os cerrados do Brasil Central e as florestas semidecíduas do Sudeste e Sul do país (U rurahy et al. 1983; Oliveira-Filho 2006). Tal fato, associado à topografia acidentada e solos predominantemente de natureza quartzítica, permitem que a cobertura vegetal apresente-se de forma heterogênea, constituindo um mosaico de comunidades de diferentes fisionomias (Salimena-Pires 1997, Rodela 1998, Dias et al. 2002). A pesar da predominância de ambientes campestres na área do Parque, mais de $30 \%$ de sua cobertura vegetal está representada por florestas ombrófilas e matas nebulares (Fontes 1997).

A mbientes como os campos rupestres e florestas nebulares, há muito, despertam o interesse de pesquisadores devido à sua flora peculiar, caracterizada por grande diversidade de espécies e al to grau de endemismos (J oly 1970, Gentry 1992, Webster 1995, Giulietti et al. 2000). Tais fatos reforçam a necessidade de ampliação do conhecimento desses ambientes, possibilitando sua conservação e exploração racional de seus recursos.

Dada a importância desses ecossistemas, os objetivos do presente estudo foram inventariar as espécies de Bambusoideae no Parque Estadual de Ibitipoca, ampliando o conhecimento da flora agrostológica desta unidade de conservação (UC) e do estado de M inas Gerais, assim como, ampliar o conhecimento taxonômico e da distribuição geográfica das espécies de bambus representadas no Parque.

\section{M aterial e métodos}

0 relevo da Serra de Ibitipoca, M inas Gerais, é caracterizado pelas escarpas altas entre $1.200-1.800 \mathrm{~m}$ de altitude e o clima é do tipo Cwb, mesotérmico úmido, com verões amenos e invernos secos, precipitação média anual de 1.532 $\mathrm{mm}$ e temperatura média de $18,9^{\circ} \mathrm{C}$ (CETEC 1983). 0 Parque Estadual de Ibitipoca (PEIB) representa uma área de 1.488 ha. da Serra e inclui trechos dos municípios de Santa Rita de Ibitipoca e Lima Duarte $\left(21^{\circ} 40^{\prime}-21^{\circ} 44^{\prime} \mathrm{S}\right.$, $43^{\circ} 52^{\prime}$ $43^{\circ} 55^{\prime} \mathrm{W}$ ). A briga em sua área grandes extensões de campos rupestres entremeados por porções de florestas. Para maiores detal hes sobre o Parque ver M enini N eto et al. (2007a, b).

Foram realizadas seis expedições entre março de 2006 e janeiro de 2007 para a coleta do material botânico e observações das espécies no seu ambiente natural. Para a coleta dos materiais seguiu-se a metodologia descrita por Soderstrom \& Young (1983). Os espécimes coletados foram depositados nos herbários CESJ, R e RB. Também foram analisadas as coleções dos seguintes herbários: BHCB, CEPEC, CESJ, GUA, HB, HUEFS, R, RB, SP e SPF (acrônimos segundo Holmgren et al. 1990).

A terminologia morfológica adotada segue Radford et al. (1974) e L onghi-Wagner et al. (2001). A dotou-se o sistema de classificação de Poaceae proposto pelo 'G rass Phylogeny Working Group' (GPW G 2001) e para os gêneros seguiu-se o 'Catal ogue of N ew World Grasses' (J udziewicz et al. 2000).

\section{Resultados e discussão}

Foram registradas 11 espécies de $B$ ambusoideae distribuídas em quatro gêneros no PEIB. B ambuseae foi a tribo mais diversa com 10 espécies e três gêneros: Chusquea ( 5 spp.), Aulonemia (3 spp.) e M erostachys (2 spp.). Para Olyreae foi registrada apenas uma espécie, Parodiolyra micrantha (K unth) Davidse \& Zuloaga.

Quando comparada com outras áreas de M inas Gerais (Tabela 1), foi constatado que o número de espécies de $B$ ambusoideae ocorrentes no Parque é al to, considerando sua pequena área e proporção de cobertura florestal (ca. 30\% da área total). Em parte, esta riqueza pode ser explicada pela posição geográfica do Parque, que está inserido nos Domínios da Floresta A tlântica, um dos centros de diversidade de bambus (Clark 1990, Judziewicz et al. 1999) e também pela presença de florestas nebulares e ombrófilas, ambientes sabidamente ricos em espécies deste grupo (Webster 1995, Rizzini 1997).

Tabela 1: Comparação entre o número de espécies de Bambusoideae inventariados em três localidades em M inas Gerais com tamanho das áreas.

\begin{tabular}{llll}
\hline L ocalidade & $\mathbf{N}^{\circ}$ espécies & Área $\left(\mathbf{k m}^{\mathbf{2}}\right)$ & R eferência \\
\hline Parque Estadual de Ibitipoca & 11 & 14,88 & presente estudo \\
Parque Estadual do Rio Preto & 14 & 360 & Santos-Gonçalves et al. 2006 \\
Parque Estadual do Rio Doce & 15 & 108 & Viana 2005 \\
\hline
\end{tabular}


A baixa representatividade de Olyreae pode ser explicada pelas elevadas cotas altimétricas do Parque (1.050 a 1.784 m). Os membros dessa tribo são mais comuns em florestas tropicais e subtropicais de terra baixa, ocorrendo raramente acima de $1.000 \mathrm{~m}$ de altitude (Cal derón \& Soderstrom 1980).

A penas Aulonemia fimbriatifolia, Chusquea riosaltensis e C. sellowii foram encontradas tanto em ambientes de mata nebular quanto nos campos, porém, a última foi observada no campo rupestre apenas na região do Lago dos Espelhos, às margens do rio do Salto. Todas as demais espécies foram observadas apenas nas formações florestais.

A maioria das espécies registradas no PEIB apresenta distribuição restrita aos Domínios da Floresta A tlântica. Chusquea riosaltensis e Chusquea sp. são exclusivas de M inas Gerais, com populações conhecidas apenas para a Serra de I bitipoca e Serra N egra (Ferreira et al. 2008). Aulonemia amplissima ocorre apenas no Rio de J aneiro e M inas Gerais.
Chusquea capitata e C. capituliflora apresentam distribuição restrita aos Estados do Espírito Santo, M inas Gerais, Rio de Janeiro, São Paulo, Paraná e Santa Catarina. Chusquea sellowii ocorre de M inas Gerais até o R io Grande do Sul. A análise de material dos herbários e da literatura revelou também que três espécies ocorrem fora dos limites do domínio A tlântico. Aulonemia aristulata registrada nos cerrados do Brasil Central (Irwin s.n. RB 194653); Merostachys fischeriana registrada para capões de mata no interior da $B$ ahia, município de $A$ baíra, na área de transição entre o domínio do Cerrado e Caatinga (Laessoe \& Silva s.n. SPF 91496); e Parodiolyra micrantha que apresenta ampla distribuição, desde a Venezuela até o Paraguai e A rgentina (Soderstrom \& Zuloaga 1989). 0 registro de Aulonemia fimbriatifolia no Parque representa uma nova ocorrência para M inas Gerais e amplia sua distribuição geográfica, anteriormente conhecida apenas para os Estados de Santa Catarina, Paraná e São Paulo.

Chave de identificação dos gêneros e espécies de B ambusoideae ocorrentes no PEIB com base em caracteres gerais

1. Plantas sublenhosas; flores unissexuadas 11. Parodiolyra micrantha

1'. Plantas lenhosas; flores bissexuadas.

2. Colmo com entrenó fistuloso.

3. Inflorescência racemosa, pectinada; complemento de ramo com inserção apsidada nos nós do colmo; 8-125 ramos por nó Merostachys

4. Entrenó glabro, brilhante, com 30-60 cm compr.; lâmina da folha do colmo de 8-10 x 0,5-1 cm; folha do ramo com 1-2 cm larg.; complemento de ramo com 26-125 ramos por nó 9. M. fischeriana

4'. Entrenó levemente escabro com tricomas esparsos, opaco, com 19-34 cm compr.; lâmina da fol ha do colmo de 4-5 x 3-4,5 cm; fol ha do ramo com 2-4 cm larg.; complemento de ramo com 8-10 ramos por nó 10. M. fistulosa

3'. Inflorescência em panícula laxa; complementos de ramo sem inserção apsidada nos nós do colmo, um ramo por nó Aulonemia

5. Colmo escandente desde a base, 2-3 mm de compr. 2. A. aristulata

5'. Colmo ereto na base com ápice arqueado e escandente, 0,7-1,5 cm de compr..

6. Entrenó levemente escabro; fol ha do colmo com lígula de 0,2-1 mm compr., fímbrias de 1-5 mm compr.; fol ha do ramo lanceolada a linear-lanceolada, base da lâmina foliar com margem fimbriada 3. A. fimbriatifolia

6'. Entrenó glabro; fol ha do colmo com lígula de 1-3 mm compr., fímbrias de 7-9 mm compr.; folha do ramo oval-lanceolada, base da lâmina foliar com margem não fimbriada 1. A. amplissima

2'.Colmo com entrenó sólido Chusquea

7. Inflorescência capitada; glumas I e II não escamiformes de 1-5 mm compr.

8. Inflorescência com 1-1,5 cm compr.; glumas I e II múticas, agudas 7. C. sellowii

8'. Inflorescência com 1-2,5 cm compr.; glumas I e II aristadas.

9. A rista das glumas I e II 3-5 $\mathrm{mm}$ compr. 4. C. capitata

9'. A rista das glumas I e II até $0,7 \mathrm{~mm}$ compr. 5. C. capituliflora

7'. Inflorescência em panícula aberta ou contraída; glumas I e II escamiformes de 0,2-0,4 mm compr.

10. Planta escandente; ramificação infravaginal; inflorescência em panícula aberta, ramos inferiores reflexos na maturidade 8. Chusquea sp.

10'. Planta arbustiva, ereta; ramificação intravaginal; inflorescência em panícula contraída, ramos inferiores não reflexos na maturidade 6. C. riosaltensis 
Chave de identificação dos gêneros e espécies de B ambusoideae ocorrentes no PEIB com base em caracteres vegetativos

1. Planta sublenhosa; lígula externa ausente 11. Parodiolyra micrantha

1'.Planta lenhosa; lígula externa presente.

2. Colmo com entrenó fistuloso.

3. Complemento de ramo com inserção apsidada nos nós do colmo; 8-125 ramos por nó M erostachys

4. Entrenó glabro, brilhante, com 30-60 cm compr.; lâmina da folha do colmo de 8-10 x 0,5-1 cm; fol ha do ramo com 1-2 cm larg.; complemento de ramo com 26-125 ramos por nó 9. M. fischeriana

4'. Entrenó levemente escabro com tricomas esparsos, opaco, com 19-34 cm compr.; lâmina da folha do colmo de 4-5 x 3-4,5 cm; folha do ramo com 2-4 cm larg.; complemento de ramo com 8-10 ramos por nó 10. M. fistulosa

3'. Complemento de ramo sem inserção apsidada nos nós do colmo, um ramo por nó Aulonemia

5.Colmo escandente desde a base, 2-3 mm de compr.etro; fímbrias da folha do ramo com

2-4 mm compr. 2. A. aristulata

5'. Colmo ereto na base com ápice arqueado e escandente, $0,7-1,5 \mathrm{~cm}$ de compr.; fímbrias da fol ha do ramo com 4-7 mm compr.

6. Colmo com entrenó levemente escabro; folha do colmo com lígula de 0,2-1 mm compr.; fímbrias de 1-5 mm compr.; folha do ramo lanceolada a linear-lanceolada, base da lâmina foliar com margem fimbriada 3. A. fimbriatifolia

6'. Colmo com entrenó glabro; fol ha do colmo com lígula de 1-3 mm compr.; fímbrias de 7-9 mm compr.; fol ha do ramo oval-lanceolada, base da lâmina foliar com margem não fimbriada 1. A. amplissima 2'. Colmo com entrenó sólido Chusquea

7. Planta arbustiva, ereta; ramificação intravaginal 6. C. riosaltensis

7'. Planta escandente, trepadeira; ramificação infravaginal.

8. Folha do ramo com bainha de margem glabra.

9. Pescoço do rizoma $0,3-0,5 \mathrm{~cm}$ compr.; colmo com até $0,6 \mathrm{~cm}$ de compr.., glabro passando a escabro; folha do colmo com bainha de margem glabra, lâmina 0,5-4 cm compr.; 9-13 ramos por nó

9'. Pescoço do rizoma 1,8-2,2 cm compr.; colmo com 0,8-2 cm de compr.., fortemente escabro; fol ha do colmo com bainha de margem ciliada, lâmina 3-8 cm compr.; 15-23 ramos por nó 5. C. capituliflora

8'. Folha do ramo com bainha de margem ciliada.

10. Colmo escabro com tricomas densos abaixo dos nós, esparsos em direção ao nó inferior; folha do colmo 6-10 cm compr., bainha de margem ciliada; ramos 12,5-46 cm compr.; bainha da fol ha de ramo glabra, lígula externa 0,5-2 mm compr., lígula interna 1-9 mm compr. 8. Chusquea sp.

10'. Colmo glabro a levemente escabro; fol ha do colmo $11-18 \mathrm{~cm}$, bainha de margem glabra; ramos com 10-13 cm compr.; bainha da folha de ramo escabra, lígula externa 0,2-0,3 mm compr., lígula interna ca. 0,5 mm compr. 7. C. sellowii

Aulonemia Goudot

Aulonemia é formado por aproximadamente 60 espécies (Clark et al. 2007). Distribui-se do sul do México ao sul do Brasil, sendo o sudeste brasileiro um dos centros de diversidade do grupo (Calderón \& Soderstrom 1980, Soderstrom et al. 1988, Clark 1995, Judziewicz et al. 1999). Caracteriza-se por apresentar em cada nó do colmo um ramo dominante único, fortemente divergente, muitas vezes tão bem desenvolvido quanto o colmo principal (J udziewicz et al. 1999). N o B rasil, são relacionadas 10 espécies (Filgueiras $\&$ Santos-G onçalves 2004), três delas representadas no PEIB.
1. Aulonemia amplissima (Nees) McClure, Smithsonian Contr. B ot. 9: 56. 1973.

= Arundinaria amplissima N ees, Linnea 9(4): 479. 1834.

Fig. 1 A-B.

Bambu lenhoso. Rizoma paquimorfo, pescoço 0,5-1,3 $\mathrm{cm}$ compr. Colmo às vezes com os primeiros nós geniculados, ereto na base, escandente acima, 6-8 m compr., 1-1,5 cm compr.., entrenó 25-64 cm compr., verde passando a roxo, glabro, fistuloso. Folha do colmo com bainha glabra em ambas as faces, margem glabra, $12-20 \times 4-6 \mathrm{~cm}$; lígula interna membranosa, 1-3 mm compr.; fímbrias 7-9 mm compr., base livre, ápice reto ou reflexo, verdes; lâmina ereta ou reflexa, persistente, 2-14 x 0,3-5 cm, glabra em ambas as 
faces a levemente escabra na face abaxial, margem escabra. Folha do ramo com bainha quilhada, glabra, às vezes com uma faixa de tricomas curtos na margem, margem ciliada na base; lígula externa 0,4-0,7 mm compr.; lígula interna membranosa, 0,8-2 mm compr.; fímbrias decíduas, 4-7 mm compr., base cilíndrica, livre, ápice reto ou reflexo, verdes; lâmina 13-24 cm x 3-6 cm, oval-lanceolada, ápice acuminado, base simétrica sem fímbrias marginais, face adaxial glabra, face abaxial levemente escabra com faixa verde escuro em uma das margens, margem escabra. Inflorescência não observada.

M aterial examinado: M inas Gerais: Lima Duarte, Parque Estadual do Ibitipoca, Ponte de Pedra, 2.II.1991 (veg.), L.G. Clark \& M. Morel 778 (B HCB, ISC n.v., RB, SP, SPF); Gruta dos Três A rcos, 30.IV.1991 (veg.), R.C. O liveira 25 (CES), R); M ata Grande, 7.III.2006 (veg.), F.M . Ferreira et al. 979 (CES), R); idem, 30.VI.2006 (veg.), F.M . Ferreira et al. 1052 (CES), R, RB); idem, 30.VI.2006 (veg.), F.M. Ferreira et al. 1053 (CESJ, R, RB); Gruta dos Viajantes, $19 . I X .2006$ (veg.), F.M. Ferreira et al. 1128 (CES), R, RB ); idem, 28.III.2006 (veg.), F.M. Ferreira et al. 1073 (CES), R).

Material adicional selecionado: M inas Gerais: Itamonte, Parque Nacional do Itatiaia, 11.II.1990 (fl.), L.G. Clark 665 (RB); Poços de Caldas, Serra de São Domingo, 27.II.1991 (fl.), L.G. Clark 836 (RB ); sem município, Serra do Picu, IV.1874 (fl.), C.A.W. Schwacke s.n. (RB 74493). Rio de Janeiro: I tatiaia, entre Macieira e Mont Serrat, 31.VII.1925 (fl.), M.G. Kuhlmann s.n. (RB 48207); Serra do Itatiaia, III.1894 (fl.), E. Ule s.n., (R 4239); N ova Friburgo, M ata do Registro, 10.V.1927 (fl.), M. Bandeira S.n. (RB 78968); Rio de Janeiro, estrada entre o Rio de J aneiro e Petrópolis, Carangola, XI.1943 (fl.), 0.C. Góes 789 (RB); Teresópolis, Pedra Chapadão, 9.X.1929 (fl.), A.C. Brade 9606 (R, HB ); idem, Parque Nacional da Serra dos Órgãos, 11.II.1991 (fl.), L.G. Clark 798 (RB).

Aulonemia amplissima é exclusiva do Brasil com ocorrência restrita aos estados de $M$ inas Gerais e Rio de J aneiro (Judziewicz et al. 1999). No Parque, foi observada apenas associada à vegetação lenhosa e próxima a cursos d'água, ocorrendo em floresta nebular e ombrófila. Forma grandes touceiras, os colmos atingem o estrato médio da vegetação e formam denso emaranhado.

Em fevereiro de 1991, plântulas crescendo sob touceiras mortas foram observadas na região da Ponte de Pedra e Gruta do M onjolinho (Clark \& M orel 778). De acordo com informações no rótulo da exsicata, as populações de Aulonemia amplissima do PEIB poderiam ter florescido por volta de 1989 ou 1990. Porém, durante o desenvolvimento do presente estudo, nenhuma população foi observada em flor.

Difere das demais espécies do gênero encontradas no Parque pelos colmos com entrenós levemente escabros, foIhas do colmo com lígula de 1-3 mm comprimento, fímbrias de 7-9 mm comprimento e fol has do ramo oval-Ianceoladas.

2. Aulonemia aristulata (Döll) M cClure, Smithsonian Contr. B ot. 9: 56. 1973.

$=$ Arundinaria aristulata Doell in Mart. \& Eichl., Fl. bras. enum. pl. 2(3): 165. 1880.

Fig. 1 C-D.
Bambu lenhoso. Rizoma não observado. Colmo escandente, 3-8 m compr., 2-3 mm compr.., entrenó 15-27 cm compr., verde maculado de amarelado e roxo, glabro, liso a levemente rugoso, fistuloso. Folha do colmo com bainha levemente rugosa na base passando a lisa em direção ao ápice com tricomas esparsos, margem ciliolada, 5-6 x 0,7-2 cm; lígula interna membranosa, 0,6 mm compr.; fímbrias $1-2 \mathrm{~cm}$ compr., base livre, ápice reto ou circinado, arroxeadas na base, amareladas no ápice; lâmina reflexa, decídua, 4-7 x 2-3 cm, glabra em ambas as faces, margem escabra. Folha do ramo com bainha levemente quilhada, lisa a levemente rugosa na base passando a levemente escabra no ápice, às vezes com tricomas esparsos mais densos na nervura central, margem ciliada; lígula externa ca. 0,5 mm compr.; lígula interna membranosa, 0,3-0,5 mm compr.; fímbrias persistentes, $2-4 \mathrm{~cm}$ compr., base cilíndrica, livre, ápice reto ou circinado, estramíneas; lâmina 12-19 x 1-3 cm, lanceolada, ápice acuminado, base assimétrica sem fímbrias marginais, face adaxial glabra a levemente escabra nas margens, face abaxial pubescente com tufo de tricomas na base e com faixa verde escuro em uma das margens, margem escabra. Inflorescência paniculada, laxa, $15-27 \mathrm{~cm}$ compr. E spiguetas 3-5-floras com uma flor rudimentar apical, flores hermafroditas. G lumas duas, desiguais; gluma I mucronada, 3-4 x 1-2 mm, 3-5-nervada, glabra, levemente escabra no ápice da nervura central; gluma II aristada, 6-7 x 2-3 mm, 6-7-nervada, arista 3-4 mm compr., glabra. Lema 6-10 x 2-3 $\mathrm{mm}, 7$-nervado, arista 4-6 mm compr., levemente rugoso com tricomas na base e margens, maculado. Pálea 6-7 × $2 \mathrm{~mm}$, 2-(4)-nervada, quilhada, glabra, quilha ciliada no ápice, levemente maculada. C ariopse não observada.

M aterial examinado: M inas Gerais: Lima Duarte, Parque Estadual do Ibitipoca, em mata, 2.II.1991 (fl.), L.G. Clark \& M. Morel 782 ( $B H C B, I S C$ n.v., R, RB); trilha entre o núcleo administrativo para 0 estacionamento, próximo à gruta dos Coelhos, $20 . \mathrm{VI} .1991$ (fl.), R.C. Oliveira 22 (CESJ); estrada para o alojamento, 3.XI.1991 (fl.), R.C. Oliveira 53 (CESJ); mata nebular ao lado da casa do pesquisador, 21.IX .2006 (veg.), F.M . Ferreira et al. 1152 (CES), R, RB); mata baixa com candeia próximo à gruta dos Coelhos, 22.I.2007 (fl.), F.M . Ferreira et al.1200 (CES), R, RB).

Material adicional examinado: Distrito Federal: S.I., 25.X.1965 (fl.), H. S. Irwin S.n. (RB 194653). Espírito Santo: Linhares, Reserva Biológica de Sooretama, Mata do Cupido, 15.111 .1972 (fl.), T.R. Soderstrom et al. 1901 (CEPEC); M inas Gerais: Caldas, II.1815 (fl.), A.G. Regnell s.n. (R 6012); Carangola, Parque Nacional do Caparaó, 19.XI.1988 (fl.), L. Krieger s.n. (CESJ 23150, CEPEC); Conceição do M ato Dentro, 24.X.1997 (fl.), Serra do Cipó, R. C. Forzza 353 (SPF); Felício dos Santos, A PA Felício, Cachoeira do Sumidouro, 10.VI.2006 (veg.), P.L. Viana 2421 (BHCB); N ova Lima, Reserva B iológica M ata do Jambreiro, 19.VI.1991 (fl.), P.M . Andrade 1319 (SPF); Santana do Riacho, Serra do Cipó, Santana do Pirapama, Fazenda Inhame, 22.III.1982 (fl.), H.M. Longhi-Wagner CFSC 8270 (SPF). Rio de J aneiro: Itatiaia, M aromba, 25.X.1928 (fl.), Porto 1832 (RB); Rio de Janeiro, Jardim Botânico do Rio de Janeiro, XI.1943 (fl.), F.A. M cClure 21293 (RB); estrada entre o Rio de Janeiro e Petrópolis, Carangola, M orro do J uiz, XII.1943 (fl.), Góes 1031 (RB). São Paulo. São B ernardo, 26.X.1913 (fl.), A.C. Brade 6723 (R); sem município, Estação Biológica do A lto da Serra, 29.VI.1948 (fl.), A.B. J oly s.n. (SPF 84535). Paraná: J aguariaiva, 24.XI.1987 (fl.), G. Hatschbach 51734 (HUEFS, M B M n.v.). 
Aulonemia aristulata á uma espécie exclusiva do Brasil distribuída da região central ao sul (Smith et al. 1981, Judziewicz et al. 1999). No PEIB, essa espécie foi observada no interior e borda de floresta nebular. U ma grande população da espécie também foi observada no fragmento de mata contígua à mata da portaria, fora dos limites do Parque. Aulonemia aristulata apresenta hábito escandente, atinge 0 estrato médio da vegetação e forma um denso taquaral.

$M$ aterial fértil foi coletado em fevereiro (Clark \& M orel 782), junho e novembro de 1991 (O liveira 22 e 53, respectivamente) e em janeiro de 2007 (Ferreira et al. 1200), porém, de acordo com as informações nos rótulos das exsicatas, não foi observada floração gregária para as populações do Parque, o que pode indicar florações esporádicas.

Espiguetas local izadas nos nós inferiores do colmo foram observadas, tanto acima do solo quanto nos colmos soterrados pela serrapilheira (Ferreira 1200). Não há relatos na literatura de inflorescências subterrâneas em Aulonemia.

Aulonemia aristulata diferencia-se das demais espécies do gênero encontradas no PEIB pelo colmo de 2-3 mm de compr.etro e fímbrias das fol has do ramo com 2-4 mm de comprimento.

3. Aulonemia fimbriatifolia L.G. Clark, Rev. Brasil. B ot., 27(1): 31-32. 2004.

Fig. $1 \mathrm{E}-\mathrm{F}$

Bambu lenhoso. Rizoma paquimorfo, pescoço $1-2 \mathrm{~cm}$ compr. Colmo ereto na base, arqueando acima, 6-8 $\mathrm{m}$ compr., 0,7-1,5 cm compr.., entrenó 53-60 cm compr., verde a alaranjado, levemente escabro, fistuloso. Folha do colmo com bainha glabra em ambas as faces, margem glabra, 14-18 x 3,5-6,5 cm; lígula interna membranosa, 0,2-1 mm compr.; fímbrias 1,5-5 cm compr., base parcial ou total mente conata, ápice reto a circinado, cremes na base passando a avermel hadas no ápice; lâmina ereta ou reflexa, 2-9,5 x 0,5-2 cm, face adaxial escabra, face abaxial glabra, margem escabra. Folha do ramo com bainha levemente quilhada, glabra, margem glabra; lígula externa 0,5 mm compr.; lígula interna membranosa, 0,3-0,7 mm compr.; fímbrias persistentes, 4-7 cm compr., base achatada, às vezes conata, ápice reto ou circinado, cremes na base passando a avermel hadas no ápice; lâmina 19-33 x 2-4 cm, lanceolada ou linear a lanceolada, ápice longo-acuminado, base assimétrica com fímbrias marginais, glabra em ambas as faces, face abaxial com faixa verde escuro em uma das margens, margem escabra. Inflorescência não observada.

Material examinado: M inas Gerais: Lima Duarte, Parque Estadual do Ibitipoca, próximo à Cachoeira dos Macacos, interior da mata, 7.III.2006 (veg.), F.M . Ferreira et al. 976 (CESJ, R); trilha do Monjolinho para J anela do Céu, 29.III.2006 (veg.), F.M. Ferreira et al. 1093 (CESJ, R); Gruta dos Viajantes, 29.V I.2006 (veg.), F.M . Ferreira et al. 1050 (RB).

Material adicional examinado: M inas Gerais: Felício dos Santos, APA Felício dos Santos, Cachoeira do Sumidouro, 10.VI.2006 (veg.), P.L. Viana et al. 2519 (B HCB ). São Paulo: São Paulo, Barreiro, Serra da B ocaina, s.d. (veg.), S. Viana 2965 (R). Paraná: Campina Grande do Sul, Serra do Ibitiraquire, subida para o Pico do Paraná, 14.V II.1996 (fl.), 0.S. Ribas \& F. Schwerdt 1448 (SPF).

De acordo com Clark (2004), Aulonemia fimbriatifolia ocorre de Santa Catarina até São Paulo. A través da análise das coleções dos herbários e das coletas realizadas no PEIB, pode-se verificar a ocorrência dessa espécie também para 0 estado de M inas Gerais. No PEIB, A. fimbriatifolia foi observada no interior da mata da Cachoeira dos $M$ acacos e Gruta dos Viajantes e no campo na região do M onjolinho, sempre próxima a cursos d'água.

Clark (2004) descreveu o complemento de ramo de A. fimbriatifolia como surgindo de um promontório e raramente 0 ramo primário rebrotando no nó basal, característica também observada nos espécimes do PEIB analisados. Foi coletada apenas em estado vegetativo. Contudo, pode ser facilmente diferenciada das demais espécies do gênero encontradas no Parque pelas lâminas das folhas do ramo com margem fimbriada na base.

\section{Chusquea K unth}

Chusquea é o maior gênero de $B$ ambusoideae com aproximadamente 140 espécies restritas ao Novo Mundo (J udziewicz et al. 1999). 0 gênero distribui-se do $M$ éxico a A rgentina e Chile, e apresenta a maior amplitude latitudinal $\left(24^{\circ} \mathrm{N}\right.$ a $47^{\circ} \mathrm{S}$ ) e altitudinal ( 0 a 4,000 m) entre os bambus (Soderstrom et al. 1988; Clark 1989, 1992, 1995; J udziewicz et al. 1999). A s espécies do gênero são geral mente associadas a florestas montanas, com muitas delas, especialmente de C husquea subg. Swallenochloa, características de campos de altitude do B rasil e dos páramos A ndinos (Clark 1989). Embora os A ndes tenham sido considerados o principal centro de diversidade de Chusquea (Clark 1995), o sudeste do B rasil, com 36 espécies descritas e, pelo menos 12 não descritas, parece ser a área que abriga a mai or riqueza do gênero (L. G. Clark, comunicação pessoal).

Chusquea caracteriza-se pelos colmos sólidos e gemas múltiplas e dimórficas por nó, sendo estes, caracteres sinapomórficos para o gênero (Clark 1989, 1995).

N o B rasil são registradas 40 espécies (Filgueiras \& Santos-Gonçalves 2004), cinco representadas no PEIB.

4. C husquea capitata N ees, L innea 9(4): 489. 1834.

Nome popular: criciúma.

Fig. 2 A-B.

Bambu lenhoso. Rizoma paquimorfo, pescoço $0,3-0,5$ cm compr. Colmo escandente, 7-12 m compr., ca. 0,6 compr.; entrenó 21-44 cm compr., verde com faixa azulada abaixo do nó, glabro acima do nó passando a fortemente escabro em direção ao nó superior, sólido. Folha do colmo $13-31 \mathrm{~cm}$ compr.; bainha fortemente escabra na face abaxial, margem glabra; lâmina 0,5-4 cm compr., fortemente escabra na face abaxial. R amificação infravaginal. Complemento de ramo 


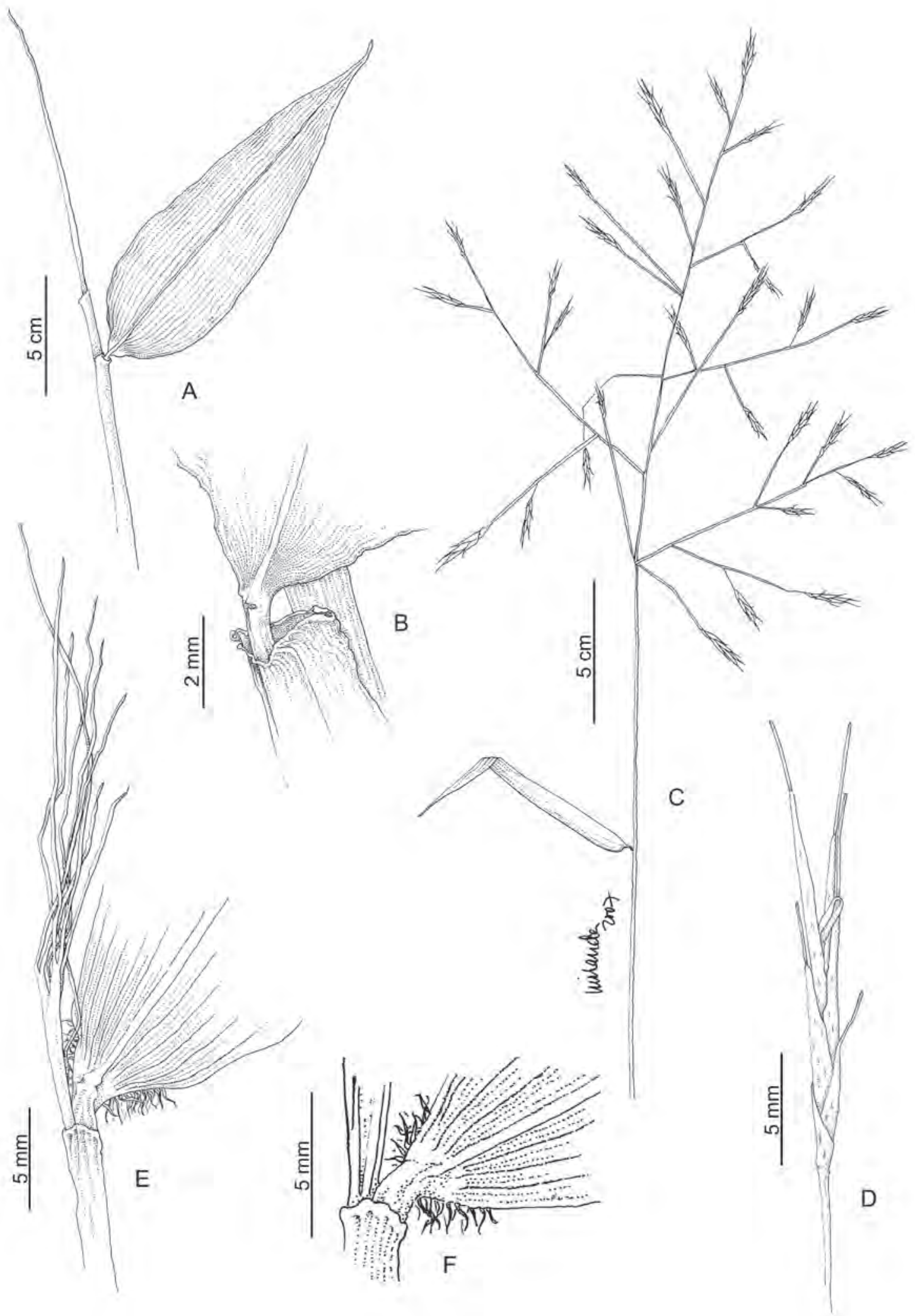

Fig. 1. A-B. Aulonemia amplissima. A. Fragmento de um ramo com folha. B. D etal he da inserção do pseudopecíolo na bainha. C-D. A. aristulata. C. Inflorescência, panícula laxa. D. Espigueta. E. A. fimbriatifolia. E. Fragmento do ramo evidenciando as fímbrias com a base conata e lâmina com base fimbriada. (A-B: Ferreira 1053. C-D: Ferreira 1200. E: Ferreira 1093). 
com 9-13 ramos por nó; ramo central não desenvolvido ou tardiamente desenvolvido, tornando-se semelhante ao colmo principal; ramos subsidiários $13-26 \mathrm{~cm}$ compr., não ramificados. Folha do ramo com bainha glabra, margem glabra; lígula externa 0,3-0,6 mm compr.; lígula interna 1-2 mm compr.; lâmina 12-16 x 1,5-2,5 cm, lanceolada, ápice acuminado, base simétrica ou acuminada, glabra em ambas as faces, face abaxial às vezes com tufo de tricomas na base, margem escabra. Inflorescência capitada, 1-2,5 cm compr. E spigueta 1-flora. G lumas quatro; glumas I e II aristadas, escabras na nervura central, margens às vezes cilioladas; gluma I 1-2 x 1-1,6 mm, 1-nervada, arista 3-5 mm compr.; gluma II 2-3 x 1,5-2 mm, 1-3-nervada, arista 3-4 mm compr.; glumas III e IV subuladas, glabras na base passando a tomentulosas no ápice, margens ciliadas; gluma III 5,5-6 x 1,5-2 mm, 5-nervada; gluma IV 6-7,5 mm x 2-3 mm, 7-nervada. L ema agudo, não convoluto, 7-8 x 2-2,5 mm, 7-nervado, glabro na base passando a tomentuloso no ápice. Pálea não convoluta, 8-8,5 x 2-2,5 mm, 7-nervada, glabra na base passando a tomentul osa no ápice, margem ciliada. Cariopse não observada.

M aterial selecionado: M inas G erais: Lima Duarte, Parque Estadual do Ibitipoca, próximo à Prainha, 3.XI.1991 (fl.), R C. O liveira \& G.M . Gomes s.n. (CESJ 25536); trilha para a Ponte de Pedra, 22.II.1992 (fl.), M. Eiterer et al. S.n. (CESJ 25702); M ata Grande, 30.VI.2006 (veg.), F.M . Ferreira et al. 1051 (CES), R, RB); idem, 21.IX.2006 (fl.), F.M. Ferreira et al. 1150 (CESJ, R, RB); mata da portaria, 23.l.2007 (fl.), F.M . Ferreira et al. 1206 (CES), R, RB); próximo à Prainha, 24.I.2007 (fl.), F.M . Ferreira et al. 1250 (RB).

Material adicional selecionado: M inas Gerais: Caldas, I.1847 (fl.), A.G. Regnell S.n. (R 4258); O uro Preto, 15.VI.1985 (fl.), M. Gomes 2562 (B HCB); Carangola, Parque Nacional do Caparaó, 15.X.1988 (fl.), M.C. B rügger s.n. (CESJ 22918); Itamonte, Borda do Parque Nacional do I tatiaia, cerca de 1-2 km do Pico das A gulhas N egras, 11.II.1990 (fl.), L.G. Clark et al. 667 (SP); Bandeira, Mata do Boi Rajado, 4.X.2003 (fl.), A. Salino et al. 8995 (B HCB ). Espírito Santo: A lfredo Chaves, Rodovia Vitor Hugo, cerca de 2-3 km de São Bento, 21.II.1990 (fl.), L.G. Clark \& M. M orel 692 (SP). Rio de Janeiro: Teresópolis, Fazenda da Boa Fé, 14.VIII.1942 (fl.), L.M. Emich s.n. (R 38411); sem município, estrada de Engenheiro Passos para São Lourenço, 16.I.1990 (fl.), L.G. Clark \& M . M orel 631 (SP). São Paulo: Santo A ndré, Estação Biológica do Alto da Serra, 6.III.1948 (fl.), M .G. Kuhlmann s.n. (SPF 81976); sem município, Serra da Bocaina, Fazenda do Bonito, XII.1930 (fl.), A. L utz \& B. Lutz S.n. (R 120888). Paraná: Tijucas do Sul, Represa Voçoroca, 15.IX.1982 (fl.), R. Kummrow 2001 (HUEFS, M BM n.v., SP).

Chusquea capitata ocorre de Minas Gerais e Espírito Santo até Santa Catarina (Judziewicz et al. 1999). No PEIB, C. capitata foi encontrada na mata baixa da Prainha, Portaria, Lago dos Espelhos, e no interior da M ata G rande onde atinge facilmente 0 estrato médio da vegetação formando densos taquarais.

Chusquea capitata pertence ao subgênero Rettbergia (J udziewicz et al. 1999). A Igumas espécies deste subgênero apresentam crescimento agressivo cobrindo grandes áreas de floresta e desempenham papel fundamental na dinâmica sucessional desses ambientes (Smith et al. 1981, Filgueiras 1988). Características como folhas do colmo escabras, ra- mificação infravaginal, ramos geniculados e gema central repetindo o colmo principal, comuns neste subgênero, são adaptações ao hábito trepador (Clark 1997).

No Parque, C. capitata foi coletada fértil em novembro de 1991 (Oliveira \& Gomes s.n. CESJ 25536) e fevereiro de 1992 (Eiterer et al. s.n. CESJ 25702), porém, não consta nos rótulos dados referentes à população. N ova coleta fértil foi realizada em setembro de 2006 e janeiro de 2007 (Fer reira et al. 1150, Ferreira et al. 1206, respectivamente), porém, não foi observada floração gregária.

Chusquea capitata assemel ha-se a C. capituliflora pelas inflorescências capitadas, partes vegetativas e hábito. Entretanto, difere pelos rizomas com pescoço mais curto, 0,3-0,5 $\mathrm{cm}$ de comprimento, pel as bainhas das folhas dos ramos com margens glabras e aristas das glumas I e II com 3-5 mm de comprimento.

5. Chusquea capituliflora Trin., M ém. A cad. Imp. Sci. St.Pétersbourg, Sér. 6, Sci M ath., Seconde Pt. Sci. N at. 3,1: 613. 1835.

Fig. 2 C-D.

Bambu lenhoso. R izoma paquimorfo, pescoço 1,8-2,2 cm compr. Colmo escandente, 7-15 m compr., 0,8-2 cm compr.; entrenó 33-57 cm compr., verde com cera glauca abaixo das fol has do colmo, fortemente escabro, sólido. Folha do colmo 27-38 cm compr.; bainha fortemente escabra na face abaxial, margem ciliada; lâmina 3-8 cm compr., fortemente escabra na face abaxial. Ramificação infravaginal. Complemento de ramo com 15-23 ramos por nó; ramo central não desenvolvido ou tardiamente desenvolvido, tornando-se semelhante ao colmo principal; ramos subsidiários 15,5-31 cm compr., ramificados. Folha do ramo com bainha glabra, margem glabra; lígula externa 0,5 mm compr.; lígula interna 1,5-2,5 mm compr.; lâmina $12-17$ x 1,5-3 cm, lanceolada, ápice acuminado, base simétrica a assimétrica ou atenuada, glabra em ambas as faces, face abaxial com tufo de tricomas na base prolongandose brevemente na nervura central e em uma das margens, margem escabra. Inflorescência capitada, 1-2,5 cm compr.. E spiguetas 1-floras. G lumas 4; glumas I e II aristadas, setosas, margem glabra; gluma I 3-4 x 1,5-2 mm, 1-3-nervada, arista ca. 0,7 mm compr.; gluma II 3-5 x 2-3 mm, 3-nervada, arista 0,4-0,6 mm compr.; gluma III 6-7 × 3-4 mm, 5-7-nervada, obtusa, glabra, escabra no ápice; gluma IV 6-8,5 x 4-4,5 mm, 5-7-nervada, obtusa, glabra na base passando a escabra no ápice. Lema obtuso, convoluto, envolvendo totalmente a pálea, 6-8 mm compr., 7-nervado, glabro na base passando a escabro no ápice. Pálea convoluta, 5-8 mm compr., 2-(4-)8-nervada, escabra somente no dorso. C ariopse não observada.

M aterial examinado seleciondo: M inas Gerais: Lima Duarte, Parque Estadual do Ibitipoca, paredão do Rio do Salto, 2.II.1991 (veg.), L.G. Clark \& M. Morel 777 (B HCB); próxima à casa do pesquisador, $6 . I I I .2006$ (veg.), F.M. Ferreira et al. 955 (CES), R); M ata Grande, 7.III.1991 (veg.), F.M. Ferreira et al. 980 (CESJ); mata da Portaria, 23.I.2007 (veg.), F.M. Ferreira et al. 1229 (CESJ, R, RB). 
Material adicional selecionado: Minas Gerais: Conceição do M ato Dentro, 7.VIII.1933 (fl.), H. Mello-Barreto 2961 (BHCB); N ova Lima, Reserva Biológica do Jambreiro, 19.VI.1991 (fl.), P.M. Andrade 1302 (BHCB, SPF); M arliéria, Parque Estadual do Rio Doce, 21.VI.1995 (fl.), J.A. Lombardi 2877 (BHCB); Tombos, Fazenda Cachoeira, 10.VII.1935 (fl.), H. M ello-Barreto 1542 (BHCB); sem município, Fazenda Passa Três, IV.1896 (fl.), H. Magalhães S.n. (R 132041). Rio de Janeiro: N ova Friburgo, Reserva E cológica M acaé de Cima, 26.II.1994 (veg.), L.S. Sarahyba et al. 1059 (SP); Petrópolis, A raras, Vale das Videiras, 7.I.1974 (fl.), D. Sucre et al. 10596 (RB, SP); Teresópolis, Serra dos Ó rgãos, 19.X.1958 (fl.), A. C astellanos 22301 (HB, RB). São Paulo: Cunha: Parque Estadual da Serra do $M$ ar, 15.I.1990 (veg.), L.G. Clark \& M. Morel 623 (SP); Limeira, Parque Biológico Bueno M iranda, 22.V II.1952 (fl.), E. Kühn s.n. (SP 232912); Prata, 29.III.1920 (fl.), F.C. Hoehne s.n. (SP 3873); Santa Izabel, 26.VI.1952 (fl.), M.G. Kuhlmann \& P. Gonçalves 2850 (SP 153831); São Paulo, B osque da Saúde, 21.X.1926 (fl.), F.C. Hoehne s.n. (SP 22349); sem município, Via A nchieta, km 35.8, 5.III.1991 (fl.), L.G. Clark \& P. Windish 728 (SP).

Chusquea capituliflora ocorre de M inas Gerais a Santa Catarina (M cClure \& Smith 1967, Judziewicz et al. 1999). No PEIB, foi observada na mata próximo a Ponte de Pedra, na portaria, atrás dos al ojamentos e no interior da $M$ ata Grande, porém é mais freqüente fora dos limites do Parque, onde forma grandes populações.

Foi coletada fértil em fevereiro de 1991 (Clark \& Morel 777), mas não foi observada floração gregária. As coletas mais recentes constam apenas de material estéril.

C husquea capituliflora pertence ao subgênero Rettbergia (Judziewicz et al. 1999), e suas características ecológicas e morfológicas assemelham-se a C . capitata, discutidas anteriormente.

6. Chusquea riosaltensis L.G. Clark, B rittonia 44(4): 403. 1992.

Fig. 2 E-F.

Bambu lenhoso. Rizoma paquimorfo, pescoço 1-1,5 cm compr. Colmo ereto, 2-4 m compr., 0,3-1 cm compr.; entrenó 4,5-9 cm compr., verde com cera glauca abaixo da bainha da folha de colmo quando estéril, passando a alaranjado e amarelo quando fértil, glabro, liso, sólido. Folha do colmo 7-16,5 cm compr.; bainha fortemente escabra na face abaxial, margem glabra, ciliada no ápice; lâmina $2-5 \mathrm{~cm}$ compr., fortemente escabra na face abaxial, sem tufo de tricomas. Ramificação intravaginal. Complemento de ramo com 8-12 ramos por nó, ramo central $20-60 \mathrm{~cm}$ compr., ramificado, subsidiários 4-12 cm compr., não ramificados. Folha do ramo com bainha pubescente entre as nervuras, margem glabra; lígula externa 0,2 mm compr.; lígula interna 0,3-0,5 mm compr.; lâmina 2,5-6 x 0,2-0,6 cm, lanceolada, ápice subulado, base arredondada, glabra em ambas as faces, face adaxial com uma faixa escabrosa em uma das margens, face abaxial sem tufo de tricomas na base, margem escabra. Inflorescência paniculada, contraída, 2-3 cm compr. E spigueta 1-floras. G lumas quatro; glumas I ell escamiformes, 0,2-0,4 mm compr.; glumas III e IV aristadas, escabras; gluma III 3-4 x
1,5-2 mm, 1-nervada, arista 0,5-0,7 mm compr.; gluma IV 3-4 x 1-2 mm, 3-4-nervada, arista 0,6-0,8 mm compr. Lema aristado, não convoluto, $5 \times 2-3 \mathrm{~mm}, 9$-nervado, arista 0,6 mm compr., escabro. Pálea não convoluta, 4-5 x 2,5-3 mm, 4-nervada, glabra na base passando a escabra no ápice. $\mathbf{C a -}$ riopse não observada.

Material examinado selecionado: Minas Gerais: Lima Duarte, Parque Estadual do Ibitipoca, Ponte de Pedra, 2.II.1991 (veg.), L.G. Clark \& M. Morel 775 (B HCB, ISC n.v., SP); Gruta do M onjolinho, 24.XI.2004 (veg.), R.C. Forzza et al. 3675 (RB); Gruta do M onjolinho, 19.IX.2006 (veg.), F.M. Ferreira et al. 1135 (R, RB); Gruta dos Três A rcos, $20.1 X .2006$ (veg.), F.M. Ferreira et al. 1144 (R, RB); campo rupestre no aceiro norte do Parque, $20.1 X .2006$ (fl.), F.M. Ferreira et al. 1148 (CES), R, RB); idem, 24.I.2007 (fl.), F.M . Ferreira et al. 1252 (CES), R, RB).

$M$ aterial adicional examinado: M inas Gerais: Rio Preto: Serra Negra, região do B urro de Ouro, 21.I.2006 (fl.), F. Souza et al. 138 (CES), R); idem, $26 . I 1.2006$ (veg.), P.L. Viana \& N. Mota 1936 (CESJ, R).

Chusquea riosaltensis apresenta distribuição restrita ao estado de M inas Gerais, com registro apenas para a Serra do I bitipoca e Serra N egra (Ferreira et al. 2008). É uma espécie arbustiva muito freqüente no PEIB, formando grandes touceiras próximas ao rio do Salto na região da Prainha, Ponte de Pedra, Lagos dos Espel hos, no campo rupestre no extremo norte do Parque e em borda de matas nebulares entre $0 \mathrm{M}$ onjolinho e a J anela do Céu (Ferreira et al. 2008).

Clark (1992) referiu que as populações dessa espécie floresceram de forma gregária em 1987 e 1988. M aterial fértil foi coletado em fevereiro de 2004 (D ias-M ello et al. 156) na região da J anela do Céu; em setembro de 2006 (Ferreira et al. 1148) e janeiro de 2007 (Ferreira et al. 1252), no campo rupestre no extremo norte do PEIB, mas não foi observada floração gregária. Para maiores detal hes sobre a fenologia da espécie ver Ferreira et al. (2008).

Chusquea riosaltensis pertence ao subgênero Swallenochloa e é morfologicamente similar a C. baculifera Silveira, porém, difere desta pelo porte robusto, número e comprimento dos ramos, indumento da folha de colmo e bainha da folha do ramo (Clark 1992).

Chusquea riosaltensis difere das demais espécies do gênero encontradas no PEIB principalmente pelo hábito arbustivo e ramificação intravaginal.

7. Chusquea sellowii Rupr., B ambuseae 35. 1839.

Fig. 2 G-H.

Bambu lenhoso. R izoma paquimorfo, pescoço $1-1,5 \mathrm{~cm}$ compr. Colmo ereto na base escandente acima, 2-8 $\mathrm{m}$ compr., 0,5-1 cm compr.; entrenó $18-25 \mathrm{~cm}$ compr., verde com cera glauca em baixo da bainha da folha de colmo, glabro a levemente escabro, sólido. Folha do colmo $11-18 \mathrm{~cm}$ compr.; bainha escabra na face abaxial, margem glabra; lâmina 1-2 cm compr., fortemente escabra na face abaxial. Ramificação infravagianal. Complemento de ramo com 13-30 ramos por nó; ramo central não desenvolvido ou tardiamente 
desenvolvido, tornando-se semel hante ao colmo principal; ramos subsidiários $10-13 \mathrm{~cm}$ compr. Folha do ramo com bainha escabra, margem ciliada; lígula externa 0,2-0,3 mm compr.; lígula interna 0,5 mm compr.; lâmina 5-7 x 0,5-0,7 $\mathrm{cm}$, lanceolada, ápice acuminado, base simétrica a assimétrica ou atenuada, face adaxial glabra, às vezes com uma faixa escabrosa em uma das margens, face abaxial glabra à tomentulosa, com tufo de tricomas na base, margem escabra. Inflorescência capitada, 1-1,5 cm compr.. E spigueta 1-floras. G lumas 4; glumas I e II múticas, agudas, setosas, 1-1,5 x 1-1,5 mm; gluma I 1-2-nervada; gluma II 1-nervada; glumas III e IV obtusas à mucronadas, glabras na base e dorso, escabras lateralmente na porção superior; gluma III 3-4 × $2 \mathrm{~mm}$, 3-(5-)nervada; gluma IV ca. 3,5-4 x 2,5 mm, 3-5-nervada. Lema obtuso, não convoluto, 5-6 x 3,5 mm, 3-4-nervado, glabro na base e dorso, escabro lateralmente na porção superior. Pálea não convoluta, 5-6 x 3-4 mm, 2-(4-)nervada, glabra na base, escabra no ápice. Cariopse 4-4,5 x 1,5 mm, fusiforme, vinácea.

Material examinado selecionado: M inas Gerais: Lima Duarte, Parque Estadual do Ibitipoca: Ponte de Pedra, 2.II.1991 (veg.), L.G. Clark \& M. Morel 779 (BHCB, ISC n.v); Prainha, 3.XI.1991 (veg.), R.C. Oliveira 58 (CESJ); Cachoeirinha, 31.III.2004 (fl., fr.), F.M. Ferreira et al. 730 (RB); Gruta dos Três A rcos, 26.V III.2004 (fl., fr.), R.C. Forzza et al. 3524 (RB); Lagos dos Espelhos, 9.III.2006 (veg.), F.M. Ferreira et al. 1029 (CESJ, R); Prainha, 9.III.2006 (veg.), F.M . Ferrei ra et al. 1030 (CESJ, R); mata da Portaria, 23.I.2007 (veg.), F.M. Ferreira et al. 1230 $(\mathrm{R}, \mathrm{RB})$.

Material adicional selecionado: M inas Gerais: Barbacena, BR 040 próximo ao posto fiscal, 24.VII.1989 (veg.), L. K rieger S.n. (CES] 23867, R); O uro Preto, Serra do Tripuí, V III.1895 (fl.), L. Damazio 2095 (R); Santa Bárbara, Serra do Caraça, caminho para a Capelinha, 18.II.1991 (fl.), M.M. Arbo et al. 5275 (SPF). São Paulo: Campos do J ordão, Parque Estadual Campos do Jordão, 27.IX.1973 (fl.), L.E. M eIo-Filho 3948 (R); Cunha, Parque Nacional da Serra do Mar, núcleo Cunha-Indaiá, trilha para o rio Bonito, perto da pedreira, 25.III.2000 (fl.), R. Mello-Silva et al. 1791 (SPF).

Chusquea sellowii ocorre de M inas Gerais até o Rio Grande do Sul (Smith et al. 1981, Judziewicz et al. 1999). É uma espécie comum no Parque, ocorre tanto no campo rupestre à margem do rio do Salto na região do Lago dos Espelhos quanto associada à florestas ombrófilas e nebulares.

Chusquea sellowii pertence ao subgênero Rettbergia (J udziewicz et al. 1999), apresenta hábito trepador, atinge 0 estrato médio da vegetação caindo em cortinas densas.

Foi coletada fértil em março e agosto de 2004 (Ferreira et al. 730 e Forzza et al. 3524, respectivamente), mas não foi observada floração gregária nas populações do Parque.

Pode ser confundida com C. capitata e C. capituliflora devido às inflorescências capitadas e aspecto das glumas I ell. Porém, C. sellowii apresenta inflorescência com até 1,5 $\mathrm{cm}$ de compr.etro, glumas I ell múticas, colmo com até $1 \mathrm{~cm}$ de compr.etro, entrenós com $25 \mathrm{~cm}$ de comprimento e fol has do ramo menores e mais estreitas.

\section{Chusquea sp.}

Fig. 2 I-J.

Bambu lenhoso. Rizoma paquimorfo, pescoço 0,5-1 cm compr. Colmo ereto na base escandente acima, 2-8 m compr., 0,5-1 cm compr.; entrenó 18-24 cm compr., verde com manchas roxas, escabro com tricomas densos abaixo do nó tornando esparsos em direção ao nó inferior, às vezes liso quando maduro. Folha do colmo 6-10 cm compr.; bainha levemente escabra, pubescente na base, margem ciliada; lâmina 0,7-3 cm compr., glabra, tessel ada. R amificação infravaginal. Complemento de ramo com 7-25 ramos por nó; ramo central não desenvolvido ou tardiamente desenvolvido, tornando-se semelhante ao colmo principal; ramos subsidiários $12,5-46 \mathrm{~cm}$ compr., não ramificados. Folha do ramo com bainha glabra, margem ciliada; lígula externa 0,5-2 mm compr.; lígula interna 1-9 mm compr.; lâmina 5-16 x 1-2 cm, lanceolada, ápice acuminado, base simétrica a assimétrica ou arredondada a atenuada, face adaxial glabra com uma faixa escabrosa em uma das margens e em 2 a 3 nervuras laterais à nervura central, face abaxial glabra à hispidulosa, margem escabra. Inflorescência paniculada, aberta, ramos reflexos na maturidade, 6-8 $\mathrm{cm}$ compr. E spigueta 1-flora. G lumas quatro; glumas I e II escamiformes, 0,2 mm compr.; glumas III e IV aristadas, setosas na porção superior, margem ciliada no ápice; gluma III 3-4 x 1-2 mm, 1-3-nervada, arista 0,5-1 mm compr.; gluma IV 3,5-4 x 1-2 mm, 5-7-nervada, arista 0,3-0,6 mm compr. Lema curto-aristado, não convoluto, 6-7 x 3-3,5 mm, 7-nervado, arista $0,1 \mathrm{~mm}$ compr., base glabra passando a levemente setoso para o ápice. Pálea não convoluta, 5-7 x 2-2,5 mm, 2-4-nervada, escabra, setosa no ápice. C ariopse não observada.

M aterial examinado: M inas Gerais: Lima Duarte, Parque Estadual do Ibitipoca, s.I., 12.XI.1987 (veg.), P.M. Andrade et al. 1081 (B HCB, SPF); S.I., 26.V.1988 (veg.), P.M. Andrade et al. 1204 (BHCB, SPF); Gruta do Monjolinho, 2.II.1991 (fl.), L.G. Clark \& M. Morel 781 (BHCB, SP, ISC n.v.); trilha entre a Lagoa Seca e a Janela do Céu, 30.III.2004 (veg.), F.M . Ferreira et al. 684 (RB); trilha entre o M onjolinho e a J anela do Céu, 7.III.2006 (veg.), F.M. Ferreira et al. 977 (CES), R); Gruta dos Coelhos, 9.III.2006 (veg.), F.M. Ferreira et al. 1028 (CESJ, R); próximo a Gruta dos Viajantes, 19.IX.2006 (veg.), F. M. Ferreira et al. 1126 (R, RB); Gruta do M onjolinho, 19.IX.2006 (veg.), F.M. Ferreira et al. 1133 (R, RB); região da Cachoeirinha, 20.IX.2006 (veg.), F.M . Ferreira et al. 1147 (R, RB); Gruta dos Coelhos, 23.I.2007 (veg.), F.M. Ferreira et al. 1207 (R, RB).

$M$ aterial adicional examinado: M inas Gerais: Rio Preto, Serra $\mathrm{Ne}$ gra, trilha para o Ninho da Égua, na mata ciliar, 9.XI.2005 (fl.), C.N. M atozinhos et al. 255 (CES), RB, HUEFS); idem, região do Burro de O uro, 26.II.2006 (veg.), P.L. Viana \& N. M ota 1921 (CESJ, RB).

Chusquea sp. apresenta distribuição restrita ao estado de $M$ inas Gerais, com registro até o presente para a Serra de I bitipoca e Serra N egra. No PEIB, foi observada no interior e borda de mata ombrófila e nas matas nebulares das áreas mais el evadas do Parque. A presenta hábito trepador e atinge o estrato médio da vegetação e forma um denso taquaral.

Chusquea sp. é morfologicamente semelhante a $C$. attenuata (Döll) L. G. Clark e a C. meyeriana Rupr. ex Döll, 


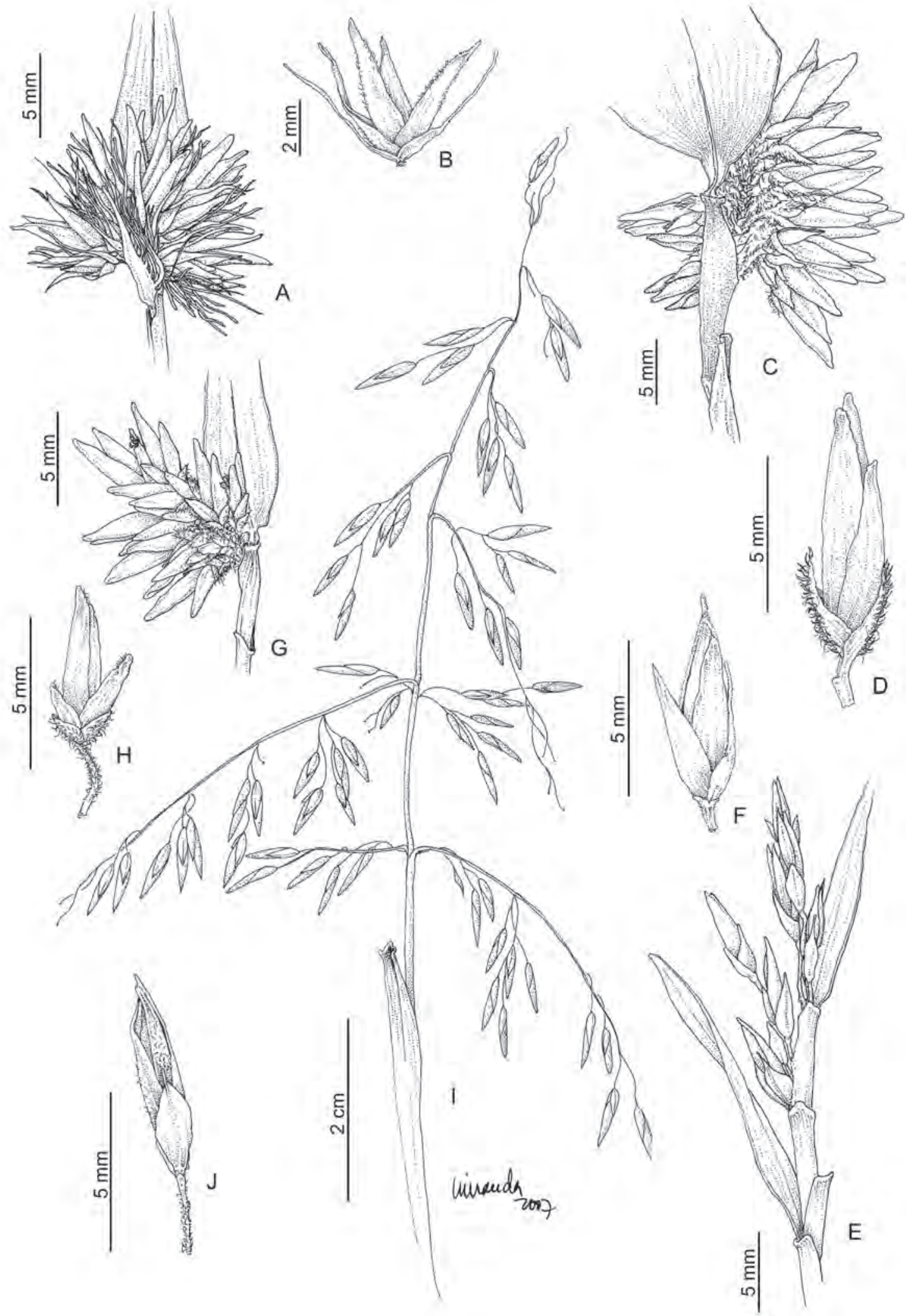

Fig. 2. A-B. Chusquea capitata. A. Inflorescência. B. Espigueta, vista lateral. C-D. C. capituliflora. C. Inflorescência. D. Espigueta, vista lateral. E-F. C. riosaltensis. E. Inflorescência. F. Espigueta, vista lateral. G-H. C. sell owii. G. Inflorescência. H. Espigueta. I-J. Chusquea sp. I. Inflorescência. J. Espiguetas, vista da gluma IV. (A -B : Ferreira 1250. C-D. Clark 783. E-F. Ferreira 1148. G-H: Ferreira 730. I-J : Clark 781). 
diferindo destas por detalhes dos ramos, folhas do colmo e tamanho das espiguetas. A ssim como Chusquea meyeriana e C. attenuata, Chusquea sp. juntamente com mais 24 espécies, não se enquadram nos três subgêneros propostos por Clark (1997).

Foi coletada fértil em fevereiro de 1991 (Clark \& M orel 781) com registro de uma floração em massa. Outra floração gregária para a espécie foi observada para as populações da Serra Negra em novembro de 2005 (M atozinhos et al. 255). Dada a proximidade entre as duas serras, cerca de $30 \mathrm{~km}$ (Ferreira et al. 2008), um possível intervalo de 14 anos entre os ciclos de floração pode ser estimado para essa espécie. São necessários mais estudos para a confirmação dos intervalos entre seu ciclo reprodutivo.

Chusquea sp. difere das demais espécies do gênero encontrados no Parque principal mente pel os col mos com tricomas abaixo dos nós, lígula interna das fol has de ramo com até $9 \mathrm{~mm}$ de comprimento e pelas inflorescências em panículas abertas.

\section{Merostachys Spreng.}

0 gênero M erostachys é formado por aproximadamente 55 espécies (J udziewicz et al. 2000). Distribui-se do sul do M éxico (Chiapas) até o nordeste da A rgentina e sul do Brasil, do nível do mar a $1.500 \mathrm{~m}$ de altitude (J udziewicz et al. 1999). Seu principal centro de diversidade localiza-se no sudeste do B rasil, especialmente nas florestas do sul da B ahia (Sendulsky 1992, Calderón \& Soderstrom 1980, Judziewicz et al.1999).

Caracteriza-se pela inserção apsidada das gemas do colmo e lâmina das folhas de colmo reflexa e Inflorescência racemosa e pectinada (M cClure 1973, J udziewicz et al. 1999).

No B rasil, são registradas 53 espécies (Filgueiras \& Santos-Gonçalves 2004), duas encontradas no PEIB.

9. Merostachys fischeriana Rupr. ex Döll in Mart. \& Eichl., Fl. bras. enum. pl. 2(3): 215. 1880.

Nome popular: taquara-lisa

Fig. $3 \mathrm{~A}-\mathrm{B}$.

Bambu lenhoso. Rizoma paquimorfo, pescoço 3-4 cm compr. Colmo ereto na base, arqueados e escandentes acima, 6-8 m compr., 1-2 cm compr.; entrenó 30-60 cm compr., verde amarelado na maturidade, glabro e brilhante, fistuloso. Folha do colmo com bainha glabra em bambas as faces, margem glabra na base, ciliada em direção ao ápice, 20-25 x 5-7 cm,; lígula interna 0,5-1 mm compr.; fímbrias 7-9 mm compr., ápice reto ou circinado, brancas na base, avermeIhadas no ápice; lâmina reflexa, decídua, 8-10 x 0,5-1 cm, face adaxial pilosa a escabra, face abaxial glabra, margem escabra. Complemento de ramo com 26-165 ramos por nó, com 13-61 cm compr. Folha do ramo com bainha glabra na base passando a estriada e pilosa no ápice, margem ciliada; lígula externa 0,1-0,3 mm compr.; lígula interna 0,3-0,5 mm compr.; fímbrias 7-19 mm compr., brancas na base, avermeIhadas no ápice; lâmina 5,5-15,5 x 1-2 cm, lanceolada, ápice acuminado, base simétrica a assimétrica, glabra em ambas as faces, face abaxial com faixa verde-escuro na margem, margem escabra. Inflorescência racemosa, pectinada, 4-7 cm compr., 33-45 espiguetas; raque e pedicelos pilosos. E spiguetas 1-floras. G lumas duas; gluma I aguda, 1-1,5 x 0,5$1 \mathrm{~mm}$, 1-nervada, glabra; gluma II aristada, 4-5 x 2-4 mm, 7-9-nervada, arista 0,4-0,5 mm compr., com tricomas esparsos na região mediana, levemente escabra na nervura central. Lema 6-7 x 3-4 mm, 10-(11-)nervado, glabro ou levemente piloso no ápice, margem ciliada no ápice. Pálea $6-7$ × 2,5$3,5 \mathrm{~mm}, 6-(8-)$ nervada, fortemente quilhada, quilha ciliada. Cariopse 4-5,5 x 2-2,5 mm, oval, parda.

M aterial selecionado: M inas Gerais: Lima Duarte: Parque Estadual do Ibitipoca, paredão do Rio do Salto, 2.II.1991 (veg.), L.G. Clark \& M. Morel 776 (BHCB, ISC n.v.); M ata Grande, 6.II.2004 (veg.), R.C. Forzza et al. 2676 (RB); mata na encosta próxima à Cachoeira dos M acacos, 7.III.2006 (fl.), F.M . Ferreira et al. 978 (CES), R); M ata G rande, 30.VI.2006 (veg.), F.M. Ferreira et al. 1055 (R, RB); idem, 21.IX.2006 (fl., fr.), F.M . Ferreira et al. 1149 (R, RB).

Material adicional selecionado: Bahia: A baíra, Tijuquinho, 17.III.1992 (veg.), T. Laessoe \& T. Silva s.n. (SPF 91496); Belmonte, $24 \mathrm{~km}$ a SW de B elmonte na rodovia para Itapebi, $24 . I I I .1974$ (fl.), R.M. Harley 17838 (CEPEC); Ibirataia, 23 km norte de Ibirataia, BR 101, Fazenda M acedônia, 4.II.1976 (fl.), C.E. Calderón et al. 2367 (CEPEC, SP). M inas Gerais: J aboticatubas, km 126 ao longo da rodovia Lagoa Santa - Conceição do M ato D entro, 7.IV.1974 (fl.), J. Semir \& M. Sazima S.n. (SP 144944); Leopoldina, 20.VI.1989 (veg.), L. Krieger \& M.C. Brügger (CESJ, SP 348485); Rio Vermelho, Serra do A mbrósio, 10.I.2006 (fl.), P.L. Viana et al. 2408 (B HCB). Rio de Janeiro: Nova Friburgo, M acaé de Cima, 10.V III.1990 (veg.), C.H.B. Correia s.n. (SP 367118); Petrópolis, Vale das Videiras, 6.VII.1974 (fl.), D. Sucre et al. 10649 (RB, SP). Paraná: Itacaré, rodovia de Itacaré para Curitiba, km 207, entre Jaguariaiva e Piraí, R io L ambari, 29.I.1990 (veg.), P. Windisch \& L.G. Clark 5638 (ISC n.v., RB).

De acordo com Judziewicz et al. (1999), M erostachys fischeriana, ocorre apenas no estado de M inas Gerais. A través de análise de material de herbário e literatura (Renvoize 1984, Pinto 1990), pode-se verificar que esta espécie apresenta uma distribuição mais ampla, com registros para os estados da B ahia, Rio de J anei ro e Paraná. No PEIB, M. fischeriana ocorre no interior da mata da encosta da Cachoeira dos $M$ acacos, porém, é mais freqüente no interior da M ata Grande, onde, juntamente com C. capitata, forma densos taquarais que cobrem a vegetação por completo em determinados trechos. Touceiras desta espécie também foram observadas nas matas fora dos limites do Parque.

De acordo com o material examinado, é possível que esta espécie tenha iniciado seu ciclo de floração em 2005 (DiasM elo et al. 222, material com inflorescências jovens), que se estendeu até 2007. Neste período, a maioria das populações observadas estava em estágio reprodutivo. Em março de 2006, foram observadas flores em antese (Ferreira et al. 978 e 1057). Frutos foram encontrados em novembro de 2006 (Ferreira et al. 1149). 0 diásporo é formado pelo lema e a pálea que caem juntamente com a cariopse e as glumas 
continuam presas à ráquis. Em janeiro de 2007, algumas touceiras no interior da M ata Grande já apresentavam flores passadas e um início de senescência.

$M$ erostachys fischeriana assemelha-se tanto vegetativamente quanto na parte reprodutiva a M. petiolata Döll. Entretanto, essa espécie apresenta complementos de ramo mais numerosos e delgados, as inflorescências são mais estreitas e o colmo é escabro.

Merostachys fischeriana difere de $M$. fistulosa principalmente pelos complementos de ramos mais numerosos, rizomas com pescoço mais curto, entrenó liso e brilhante e fol has de ramo mais estreitas.

10. Merostachys fistulosa Döll in Mart. \& Eichl., Fl. bras. enum. pl. 2(3): 209. 1880.

Nome popular: taquara-lixa

Fig. 3 C-D.

Bambu lenhoso. Rizoma paquimorfo, pescoço $4-6 \mathrm{~cm}$ compr. Colmo ereto na base, arqueado e escandente acima, 6-8 m compr., 1-1,5 cm de compr.; entrenó 19-34 cm compr., verde azulado na maturidade, levemente escabro com tricomas esparsos, opaco, fistuloso. Folha do colmo apresentando bainha com tricomas curtos e esparsos na face abaxial, mais densos na base, margem glabra, $10-13$ x 4,5-5 cm; lígula interna 1-2 mm compr.; fímbrias 9-12 mm compr., ápice reto ou circinado, estramíneas; lâmina reflexa, decídua, 4-5 x 3-4,5 cm, face adaxial com tricomas esparsos na base, glabra no restante, face abaxial com tricomas esparsos, margem escabra. Complemento de ramo com 8-10 ramos por nó, com 34-66 cm compr. Folha do ramo com bainha rugosa, estriada, pilosa na margem e ápice, margem ciliada; lígula externa 0,1-0,2 mm compr.; lígula interna 1-2 mm compr.; fímbrias 9-12,5 mm compr., estramíneas; lâmina 13-18 x 2-4 $\mathrm{cm}$, lanceolada, ápice acuminado, base simétrica, face adaxial glabra com tufo de tricomas na base da lâmina, face abaxial glabra com tufo de tricomas na base da lâmina e faixa verde-escuro na margem, margem escabra. Inflorescência não observada.

M aterial examinado: M inas Gerais: Lima Duarte: Parque Estadual do I bitipoca, M ata Grande, 21.IX.2006 (veg.), F.M . Ferreira et al. 1151 $(R, R B)$.

M aterial adicional examinado: M inas Gerais: sem município, s.d., (fl.), A.G. Regnell s.n. (R 4254). São Paulo: Itapira, Forões, 21.X II.1987 (fl.), E.L.M . Catharino S.n. (SP 246019); Campinas, Instituto A gronômico, M ata Santa Elisa, 17.I.1994 (fl.), L.G. Clark \& A. Salgado 1177 (ISC n.v., SP).

Judziewicz et al. (1999) referem Merostachys fistulosa apenas para M inas Gerais. Com base no material examinado nos herbários e literatura (Pereira 1941), pode-se verificar que esta espécie também ocorre no estado de São Paulo e Paraná. No PEIB, foi observada apenas uma pequena população no interior da M ata Grande.

M erostachys fistulosa apresenta os colmos eretos na base, arqueados e escandentes acima. Pode ser diferenciada de $M$. fischeriana principalmente pelos colmos verde-azulados, levemente escabros e opacos, rizomas com o pescoço mais longo (4-6 cm compr.), entrenós mais curtos (19-34 cm compr.) e complemento de ramo com 8-10 ramos por nó.

\section{Parodiolyra Soderstr. \& Zuloaga}

Parodiolyra é formado por cinco espécies amplamente distribuídas na A mérica do Sul (Soderstrom \& Zuloaga 1989). O correm do nível do mar até $1.200 \mathrm{~m}$, al gumas vezes $1.800 \mathrm{~m}$, em diferentes formações florestais e ocasional mente na savana (Soderstrom \& Zuloaga 1989; Oliveira \& L onghi-Wagner 2001). 0 gênero caracteriza-se pelas espiguetas femininas que caem inteiras pela articulação abaixo das glumas, pedicelos das espiguetas femininas filiformes, entrenó conspícuo entre a gluma superior e inferior, prolongamento da ráquila entre a gluma superior e 0 antécio e hilo com apenas $1 / 2$ a $3 / 4$ do comprimento da cariopse, nunca atingindo seu comprimento total (Soderstrom \& Zuloaga 1989).

No B rasil, ocorrem quatro espécies (Filgueiras $\&$ SantosGonçalves 2004), uma representada no PEIB.

11. Parodiolyra micrantha (Kunth) Davidse \& Zuloaga, N ovon: 590. 1999.

= Olyra micrantha Kunth in Humboltd, Bompland \& Kunth, Nov. Gen. Sp. 1: 199. 1816.

Bambu herbáceo. Colmo ereto ou inclinando-se sobre outras plantas, simples ou ramificando nos nós medianos e superiores, 1-2,5 m alt. E ntrenós 0,5-1 cm compr.. Folhas com bainhas glabras, margem glabra; lígula interna membranosa, 0,5-1 cm compr.; lâmina 15,5-19,5 x 2-4 cm, lanceolada, ápice acuminado, base si métrica a levemente assimétrica, glabra em ambas as faces, margem escabra. Inflorescência 20-24 x $8 \mathrm{~cm}$, ramos inferiores verticilados, somente com espiguetas masculinas, ramos superiores alternos, somente com espiguetas femininas. E spiguetas com flores unissexuais; espigueta masculina 6-9 $\mathrm{mm}$ compr.; lema 6-8 $\mathrm{mm}$ compr., 3-nervado, aristado, arista 1,5-2 mm compr.; pálea 6,5-7 mm compr., 2-nervada; espigueta feminina 6-7,5 mm compr.; glumas duas, aristadas, pilosas; gluma inferior 6,5-7 mm compr., 5-nervada; arista 1-1,5 mm compr.; gluma superior 4,5-5 mm compr., 3-nervada, arista 0,5-1 mm compr.; antécio ovado, castanho, escavado, 2,5-3 x 0,5-2 mm. Cariopse não observada.

M aterial examinado: M inas Gerais: Lima Duarte, Parque Estadual do Ibitipoca, M ata Grande, 24.I.2007 (fl.), F.M. Ferreira et al. 1239 (RB).

M aterial adicional examinado: M inas Gerais: Juiz de Fora, rio Paraibuna, 1895 (fl.), F.M. Gomes S.n. (RB 74475).

Parodiolyra micrantha ocorre na Colômbia, Venezuela, Peru, Bolívia, A rgentina, Paraguai e Brasil, onde pode ser encontrada em fragmentos de $M$ ata A tlântica secundária, borda de mata, sub-bosque de mata mesófila, restinga próxima à $M$ ata A tlântica, mata de brejo, cerrado e sobre rochas 


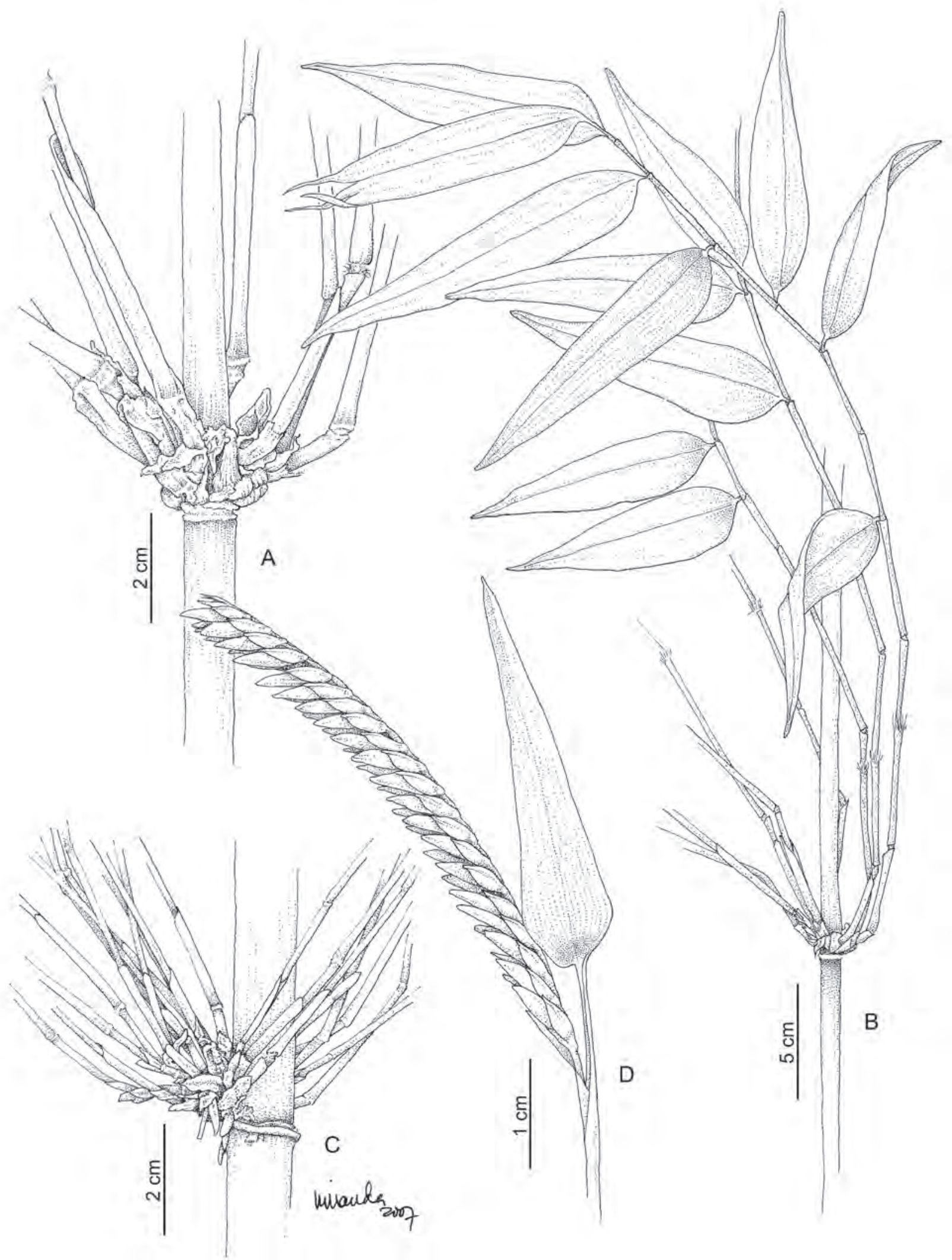

Fig. 3. M erostachys fistulosa. A . Fragmento do colmo, evidenciando a inserção apsidada dos ramos no nó. B. Fragmento do colmo, evidenciando os ramos com folhas. C-D. M. fischeriana. C. Fragmento do colmo, evidenciando a inserção apsidada dos ramos no nó. D. Folha terminal e inflorescência, vista lateral. (A-B: Ferreira 1151. C-D: Ferreira 1057). 
(Soderstrom \& Zuloaga 1989, Oliveira \& Longhi-Wagner 2001). No PEIB, a espécie foi observada apenas no interior da $M$ ata $G$ rande formando pequenas populações.

Parodiolyra micrantha assemel ha-se à $P$. colombiensis Davidse \& Zuloaga pelos antécios femininos escavados (Zuloaga \& Davidse 1999). Porém, a última apresenta espiguetas femininas menores (4,5-5 mm compr.) e glumas múticas (Zuloaga \& Davidse 1999).

A s espiguetas masculinas foram descritas a partir de F.M . Gomes s.n.(RB 74475). Ilustrações desta espécie aparecem em Soderstrom \& Zuloaga (1989).

\section{Índice de exsicatas}

(Os números entre parênteses correspondem à numeração das espécies no texto)

Andrade, A.G.: 17244 (1), 132 (5). Andrade, P.M.: 1319 (2), 1302 (5), 1081 (8), 1204 (8). A raújo, D.: 1923 (9). Arbo, M.M.: 5275 (7). Bandeira, M.: s.n. RB 78968 (1). Barbosa, E.: 126 (4), 126 (4). Brade, A.C.: 9606 (1), 6723 (2). Brügger, M.C.: s.n. CESJ 22918 (4), s.n. (RB 440065) (10). Calderón, C.E.: 2367 (9). Campos, M.T.V.A.: s.n. SPF 106748 (2). Capanema, C.: s.n. RB 5495 (2). Castellanos, A.: s.n. R 122234 (1), s.n. R 107901 (4), 22301 (5). Catharino, E.L.M.: s.n. SP 246019 (10). Clark, L.G.: 665 (1), $778(1), 798(1), 836(1), 671(2), 782(2), 692(4), 736$ (4), $698(4), 667(4), 631(4), 622(4), 681(5), 677(5), 777$ (5), 783 (5), 809 (5), 623 (5), 847 (5), 728 (5), 779 (7), 781 (8), 776 (9), 1177 (10). Correia, C.H.B.: s.n. SP 367118 (9). Damazio, L .: 2095 (7). Dias-M elo, R .: 156 (6), 222 (9). Duseir, P.: s.n. R 295 (1). Eiterer, M .: s.n. CESJ 25701 (4), s.n. CESJ 25702 (4), s.n. CESJ 25702A (4). E mench, L.M .: 130 (4), s.n. (R: 38413) (5). Emiclin, N.T.L.: S.n. R 38411 (4). Ferreira, F.M .: 979 (1), 1128 (1), 1052 (1), 1053 (1), 1073 (1), 1152 (2), 1200 (2), 976 (3), 1050 (3), 1093 (3), 1150 (4), 1051 (4), 1054 (4), 1058 (4), 1206 (4), 1250 (4), 955 (5), 980 (5), 1229 (5), 989 (6), 1135 (6), 1144 (6), 1148 (6), 1252 (6), 730 (7), 1029 (7), 1030 (7), 1230 (7), $684(8), 977$ (8), 1028 (8), 1126 (8), 1133 (8), 1147 (8), 1207 (8), 978 (9), 1055 (9), 1056 (9), 1057 (9), 1149 (9), 1151 (10). Forzza, R.C.: 353 (2); 3675 (6), 3524 (7), 2676 (9). G arcia, R.J.F.: 99 (5). Góes, O.C.: 789 (1), s.n. RB 49964 (1), 1031 (2). Gomes, F.M .: s.n. RB 74475 (11). Gomes, M.: 2562 (4). Hoehne, F.C.: s.n. SP 22349 (5). Irwin, H.S.: (RB: 194653) (2). J oly, A.B.: s.n. SPF 84535 (2). K rieger, L .: S.n. CES J 23150 (2), s.n. CESJ 23974 (2), 591 (4), s.n. RB 440069 (7), s.n. RB 440060 (7), 1317 (9), 1317 (10). Kühn, E.: s.n SP 232912 (5). Kuhlmann, M.G.: s.n. RB 48207 (1), s.n. SPF 81976 (4), 2850 (5). Kummrow. R .: 2001 (4). L aessoe, T.: s.n SPF 91496 (9). Lombardi, J .A.: 5737 (4), 2877 (5). L ondoño, X.: 715 (9). Longhi-Wagner, H.M .: s.n. CFSC 8270 (2). L utz,A.: s.n. R 120888 (4). M agalhães, H.: s.n. R 132041 (5). M arkgrat: 3740 (1). M cClure, F.A.: 21293 (2), 21277 (2). Mello-Barreto, H .: 1542 (5), 2959 (5), 2961 (5).
M ello-Silva, R .: 1791 (7). M elo, E .: 2527 (4). Melo-Filho, L.E.: 3948 (7). M exia, Y.: 5256 (9). Oliveira, R.C.: 25 (1), s.n. CESJ 23325 (2); 22 (2), 53 (2), s.n. CESJ 25536 (4), 32 (5), 54 (7), 58 (7). Porto, C.: 1832 (2). Regnell, A.G.: s.n. R 6012 (2), s.n. R 4258 (4), s.n. SP 10308 (4), s.n. R 4254 (10). Ribas, O .S.: 1448 (3), 2754 (4). Salino, A.: 8995 (4). Sarahyba, L.S.: 1059 (5). Schwacke: s.n. RB 74493 (1). Semir, J.: S.n. SP 144944 (9). Sendulsky, T.: 1424 (5), 1431 (5). Silva, J.M.: 2114 (4), 2000 (4). Sucre, D.: 10596 (5), 10649 (9). Ule, E.: s.n. R 237 (1), s.n. R 44490 (1). Viana, P.L.: 2521 (2), 2519 (3), 2408 (9). Viana, S.: 2965 (3). Windisch, P.: 5638 (9).

\section{Agradecimentos}

A o IEF-M G, em especial à administração e aos funcionários do Parque por todo apoio para o desenvolvimento deste trabal ho. A os Drs. M arcos Nadruz eTarciso Filgueiras pelas sugestões. A o Programa de Pós-graduação em Ciências Biológicas (Botânica) do M useu Nacional/UFRJ. A os curadores dos herbários visitados. A D omingos Cardoso pela ajuda com o "A bstract" e formatação das pranchas. A Pedro L. Viana pelo auxílio no trabal ho de campo. A Cláudia M iranda pelas ilustrações. A o CN Pq pel as bolsas concedidas ao primeiro e terceiro autores.

\section{Referências}

CALDERÓN, C.E. \& SODERSTROM,T.R. 1980. The genera of Bambusoideae (Poaceae) of the A merican Continent. Keys and Comments. Smithsonian Contr. Bot. 44: 1-27.

CETEC. 1983. Diagnóstico ambiental de M inas Gerais. CETEC. Belo Horizonte.

CLARK, L.G.1989. Systematics of Chusquea sect. Swallenochloa, sect. Verticilatae, sect. Serpentes and sect. Longifoliae (Poaceae: B ambusoideae). Syst. Bot. M onogr. 27: 1-127.

CLARK, L.G. 1990. Diversity and biogeography of neotropical bamboos (Poaceae: B ambusoideae). Acta Bot. Bras. 4: 125-132.

CLA RK, L.G. 1992. Chusquea sect. Swallenochloa (Poaceae: B ambusoideae) and allies in Brazil. Brittonia 44: 387-422.

CLARK, L.G. 1995. Diversity and distribution of the Andean woody bamboos (Poaceae: B ambusaeae) In S.P. Churchill, H. Balslev, E. Forero \& J. Luteyn. Biodiversity and conservation of neotropical montane forests. New York B otanical Garden. N ew York, p. 501-512.

CLARK, L.G. 1997. Diversity, biogeography and evolution of Chusquea. In G.P. Chapman (ed.) The bamboos. A cademic Press. London, p. 33-44.

CLA RK, L.G. 2004. New species of Aulonemia and Chusquea (Poaceae: $B$ ambusoideae: B ambuseae) from southeastern $B$ razil. Revista Brasil. Bot. 27: 31-36.

CLARK, L.G., ZHANG, W. \& WENDEL, J.F. 1995. A phylogeny of the grass family (Poaceae) based on ndhF sequence data. Syst. Bot. 20: 436-460.

CLARK, L.G., JUDZIEWICZ, E.J. \& TYRRELL, C.D. 2007 Auolnemia ximenae (Poaceae: B ambudoideae), a new northers $A$ ndean species with fimbriate sheath margins. Bamboo Scien. Cult. 20: 1-6. 
deWET, J.M .J. 1981. Grasses and the culture history of man. Ann. M issouri Bot. Gard. 68: 87-104.

DIAS, H.C.T., FERNANDES-FILHO, E.I., SCHAEFER, C.E.G.R. FONTES, L.E.F. \& VENTORIM, L.B. 2002. Geoambientes do Parque Estadual do Ibitipoca, município de Lima Duarte, M inas Gerais. Revista Árvore 26: 777-786.

FERREIRA, F.M., VIANA, P.L.\& CLARK, L.G. 2008. Flowering in Chusquea riosaltensis (Poaceae: Bambusoideae: Chusqueinae). Bamboo Scien. Cult. 21: 48-52.

FIL GUEIRA S, T.S. \& SANTOS-GON ÇA LVES, A.P.S. 2004. A checklist of the basal grasses and bamboos (Poaceae) in Brazil. Bamboo Scien. Cult. 18: 7-18.

FILGUEIRAS, T.S. 1988. A floração dos bambus e seu impacto ecológico. Eugeniana 15: 1-8.

FONTES, M.A. 1997. Análise da composição florística das florestas nebulares do Parque Estadual do Ibitipoca, M inas Gerais. Dissertação de M estrado, U niversidade Federal de L avras. Lavras.

GENTRY, A.H. 1992. Tropical forest biodiversity: distributional patterns and their conservational significance. Oikos 63: 19-28.

GIULIETTI, A.M., HARLEY, R.M., QUEIROZ, L.P., WANDERLEY, M.G.L. \& PIRANI, J.R. 2000. Caracterização e endemismo nos campos rupestres da Cadeia do Espinhaço. In T.B. Cavalcanti \& B.M. Walter (eds.) Tópicos atuais em Botânica. SBB, Embrapa. B rasília, p.311-318.

GRASS PHYLOGENY WORKING GROUP (GPWG). 2001. Phylogeny and subfamilies classification of the grasses (Poaceae). Ann. M issouri Bot. Gard. 88: 373-457.

HOLM GREN, P.K., HOLM GREN, N.H. \& BARNETT, L.C. 1990. Index Herbariorum: the herbaria of the world. New York Botanical Garden. New York.

JACOBS, B.F., KINGSTON, J.D. \& JACOBS, L.L. 1999. The origin of grass-dominated ecosystems. Ann. M issouri Bot. Gard. 86: 590-643.

J OLY, A.B. 1970. Conheça a vegetação brasileira. São Paulo EDUSP, Polígono. São Paulo.

JUDZIEWICZ, E.J., CLARK, L.G., LONDOÑO, X. \& STERN, M . 1999. American Bamboos. Smithsonian Institution, Washington, D.C.

JUDZIEWICZ, E.J., SORENG, R.J., DAVIDSE, G., PETERSON, P. M., FILGUEIRAS, T. S. \& ZULOAGA, F.O. 2000. Catalogue of New World Grasses (Poaceae): I. Subfamilies A nomochlooideae, Bambusoideae, Ehrhartoideae, and Pharoideae. Contr. U. S. Natl. Herb. 39: 1-128.

LONGHI-WAGNER, H.M., BITTRICHI, V., WANDERLEY, M.G.L. \& SHEPHERD, G. (eds.) 2001. Poaceae. In M.G.M. Wanderley, G.J. Shepherd \& A.M. Guilietti (org.). Flora fanerogâmica do Estado de São Paulo. FA PESP, HU CITEC. São Paul o, vol. 1, p. 1-291.

M CCLURE, F.A.\& SM ITH, L.B. 1967. Gramíneas (supl. Bambúseas). In P.R. Reitz (ed.) Flora Ilustrada Catarinense. Herbário Barbosa Rodrigues. Itajaí, 1, p. 1-78.

McCLURE, F.A. 1973. Genera of bamboos native to the New World (Gramineae: B ambusoideae). Smithsonian Contr. Bot. 9: 1-147.

MENINI NETO, L., ALVES, R.J.V., BARROS, F. \& FORZZA, R. 2007a. Orchidaceae do Parque Estadual de I bitipoca, M inas Gerais, B rasil. Acta Bot. Bras. 21: 687-696.

MENINI NETO, L., ALVES, R.J.V. \& FORZZA, R.C. 2007b. A subtribo Pleurothallidinae (O rchidaceae) no Parque Estadual de Ibitipoca, M inas Gerais, B rasil. Bol. Bot. U niv. São Paulo 25: 253-278.

OLIVEIRA, R.P. \& LONGHI-WAGNER, H.M. 2001. Parodiolyra. In H.M. L onghi-Wagner, V. Bittrich, M.G.L. Wanderley \& G.J. Shepherd (eds.). F lora fanerogâmica do Estado de São Paulo - Poaceae. FA PESP, HUCITEC. São Paulo, vol. 1, p. 47-48.

OLIVEIRA-FILHO,A.T. 2006. Catálogo das Árvores nativas de Minas Gerais mapeamento e inventário da flora nativa e dos reflorestamentos de M inas G erais. Editora U FLA . Lavras.

PEREIRA, C. 1941. Sobre as ratadas no sul do Brasil e o ciclo vegetativo das taquaras. Arq. Inst. Biol. 12: 175-196.

PINTO, G.C.P. 1990. Flora da Bahia - Gramineae. In R.J.M. Olivei- ra (ed.) Anais do $36^{\circ}$ Congresso Nacional de Botânica. IBAM A. B rasília, p. 23-32.

RADFORD, A.E., DICKINSON, W.C., MASSEY, J.R. \& BELL, C.R. 1974. Vascular plant systematics. Harper \& Row. New York.

RIZZINI, C.T. 1997. Tratado de fitogeografia do Brasil: aspectos ecológicos, sociológicos e florísticos. Â mbito Cultural. Rio de Janeiro.

RENVOIZE, S.A. 1984. The Grasses of Bahia. Royal B otanical Gardens. Kew.

RODELA, L.G. 1998. Cerrados de altitude e campos rupestres do Parque Estadual do Ibitipoca Sudeste de M inas Gerais: distribuição e florística por subfisionomias da vegetação. Revta Dept. Geogr. U niv. S. Paulo 12: 163-189.

SA LIM ENA-PIRES, F.R.G. 1997. A spectos fisionômicos e vegetacionais do Parque Estadual do I bitipoca, M inas Gerais, Brasil. In G.C. Rocha, (coord.) Anais do 1 o Seminário de Pesquisa sobre o Parque Estadual do Ibitipoca. Núcleo de Pesquisa em Zoneamento Ambiental da UFJ F. Juiz de Fora, p. 51-60.

SANTOS-GONÇALVES, A.P.S., OKANO, R.M.C., VIEIRA, M.F. \& FIL GUEIRAS, T.S. 2006. Bambus (Bambusoideae: Poaceae) do Parque Estadual do Rio Doce, M inas Gerais: Florística e M orfologia. In J.G. A Imeida \& A .A. Teixeira (eds.) Anais do Seminário Nacional do Bambu - estruturação da rede de pesquisa e desenvolvimento, Faculdade de A rquitetura e U rbanismo, U nB. Brasília, p. 43-48.

SENDULSKY, T. 1992. Merostachys burbanii (Poaceae: Bambusoideae: B ambuseae), a new species from Brazil. Novon 2: 111-113.

SHANTZ, H.L. 1954. The place of grasslands in Earth's cover of vegetation. E cology 35: 143-145.

SM ITH, L.B., WA SSH AU SEN, D.C.\& KLEIN, R.M . 1981. Gramíneas. In R. Reitz (ed.) Flora ilustrada catarinense. Herbário Barbosa Rodrigues. Itajaí, 1, p. 1-442.

SODERSTROM, T.R. 1981. Some evolutionary trends in the Bambusoideae (Poaceae). Ann. M issouri Bot. Gard. 68: 15-47.

SODERSTROM, T.R. \& CALDERÓN, C.E. 1974. Primitive forest grasses and evolution of the B ambusoideae. Biotropica 6: 141-153.

SODERSTROM, T.R. \& YOUNG, S.M. 1983. A guide to collecting bamboos. Ann. M issouri Bot. Gard. 70: 128-136.

SODERSTROM , T.R. \& ZULOAGA, F.O. 1989. A revision of the genus $O$ lyra and the new segregate genus Parodiolyra (Poaceae: $B$ ambusoideae: Olyreae). Smithsonian Contr. Bot. 69: 1-79.

SODERSTROM , T.R., JUDZIEWICZ, E.J. \& CLARK, L.G. 1988. Distribution patterns of Neotropical bamboos. In P.E. Vanzolini \& W.R. Heyer (eds.) Proceedings of a workshop on Neotropical distribution patterns. A cademia B rasileira de Ciências. Rio de J aneiro, p. 121-157.

STEBBINS, G.L. 1981. Coevolution of grasses and herbivores. Ann. M issouri Bot. Gard. 68: 75-86.

TZVELEV, N.N. 1989. The system of grasses (Poaceae) and their evoIution. Bot. Rev. 55: 142-203.

URURAHY, J.C.C., COLLARES, J.E.R., SANTOS, M.M \& \& BARRETO R.A.A. 1983. Vegetação: as regiões fitoecológicas, sua natureza e seus recursos econômicos, estudo fitogeográfico. In B rasil, M inistério das M inas e Energia, Secretaria Geral. Projeto RADAM -BRASIL, Levantamento de Recursos Naturais, vol. 32 - Rio de Janeiro/ Vitória. Brasília, p. 553-623.

VIA NA, P.L. 2005. Contribuição para o conhecimento das Poaceae no Parque Estadual do Rio Preto, M inas G erais, B rasil. Dissertação de M estrado. U niversidade Federal de M inas Gerais. B elo Horizonte.

WEBSTER, G.L. 1995. The panorama of Neotropical Cloud Forest. In S.P. Churchill, H. B alslev E. Forero \& J.L. L uteyn (eds.). Biodiversity and Conservation of Neotropical Montane Forest Biodiversity and Conservation Symposium. The New York Botanical Garden. New York, p. 53-77.

ZHANG, W. \& CLARK, L.G. 2000. Phylogeny and classification of the B ambusoideae (Poaceae). In S.W.L. J acobs \& J. Everett (eds.) Grasses: Systematics and Evolution. CSIRO. M el bourne, p. 35-39.

ZULOAGA, F.O.\& DAVIDSE, G. 1999. A new species and a new combination in the genus Parodiolyra (Poaceae: Bambusoideae: Olyreae). Novon 9: 587-591. 